University of Nebraska - Lincoln

DigitalCommons@University of Nebraska - Lincoln

Faculty Publications from the Harold W. Manter Laboratory of Parasitology

$12-1994$

\title{
Phylogenetic Systematic Analysis of the Trichostrongylidae (Nematoda), with an Initial Assessment of Coevolution and Biogeography
}

\author{
Eric P. Hoberg \\ United States Department of Agriculture,Agricultural Research Service, ehoberg@ggpl.arsusda.gov \\ J. Ralph Lichtenfels \\ United States Department of Agriculture, Agricultural Research Service
}

Follow this and additional works at: https://digitalcommons.unl.edu/parasitologyfacpubs

Part of the Biodiversity Commons, Evolution Commons, and the Parasitology Commons

Hoberg, Eric P. and Lichtenfels, J. Ralph, "Phylogenetic Systematic Analysis of the Trichostrongylidae (Nematoda), with an Initial Assessment of Coevolution and Biogeography" (1994). Faculty Publications from the Harold W. Manter Laboratory of Parasitology. 723.

https://digitalcommons.unl.edu/parasitologyfacpubs/723

This Article is brought to you for free and open access by the Parasitology, Harold W. Manter Laboratory of at DigitalCommons@University of Nebraska - Lincoln. It has been accepted for inclusion in Faculty Publications from the Harold W. Manter Laboratory of Parasitology by an authorized administrator of DigitalCommons@University of Nebraska - Lincoln. 


\title{
PHYLOGENETIC SYSTEMATIC ANALYSIS OF THE TRICHOSTRONGYLIDAE (NEMATODA), WITH AN INITIAL ASSESSMENT OF COEVOLUTION AND BIOGEOGRAPHY
}

\author{
E. P. Hoberg and J. R. Lichtenfels
}

United States Department of Agriculture, Agricultural Research Service, Biosystematic Parasitology Laboratory, BARC East, Building 1180, 10300 Baltimore Avenue, Beltsville, Maryland 20705-2350

\begin{abstract}
Phylogenetic analysis of the subfamilies of the Trichostrongylidae based on 22 morphological transformation series produced a single cladogram with a consistency index $(\mathrm{CI})=\mathbf{7 4 . 2} \%$. Monophyly for the family was supported by the structure of the female tail and copulatory bursa. Two major clades are recognized: the Cooperiinae clade with the basal Cooperiinae and Libyostrongylinae + Trichostrongylinae, and the Graphidiinae clade with the basal Graphidiinae and Ostertagiinae + Haemonchinae. Dendrograms presented by DuretteDesset $(1985)(C I=56.1 \%)$ and Lichtenfels (1987), based on the key to the Trichostrongylidae by Gibbons and Khalil (1982) $(\mathrm{CI}=59.0 \%)$, were found to be relatively inefficient in describing character evolution and in supporting putative relationships among the subfamilies. Based on the current analysis, the intestine appears to have constituted the ancestral habitat for the trichostrongylids with the stomach/abomasum having been independently colonized in each clade. Assessment of host associations suggests extensive colonization but also a high degree of coevolution with Bovidae and Cervidae for Ostertagiinae + Haemonchinae. Biogeography for this assemblage is complex, but this analysis is compatible with a Palearctic or Eurasian origin for Cooperiinae, Haemonchinae, and Ostertagiinae.
\end{abstract}

Trichostrongyle nematodes are significant parasites among sylvatic and domesticated ruminants. An understanding of phylogenetic relationships of these nematodes has a bearing on elucidating aspects of host associations, parasite behavior (including pathogenesis), epidemiology, evolution, and biogeographic history. These nematodes may also prove to be exceptionally useful in defining the distributional history for ruminants in the Holarctic, e.g., Drózdz (1967) and Hoberg et al. (1993a).

The superfamily Trichostrongyloidea Cram, 1927 constitutes one of the most diverse and complex taxa within the Strongylida or bursate nematodes (Durette-Desset, 1983, 1985). Although not adopted in the present study, recently it has been proposed that this taxon be elevated to subordinal rank as the Trichostrongylina (see Durette-Desset and Chabaud, 1993). Among the trichostrongyloids, the family Trichostrongylidae Leiper, 1912 represents groups of considerable veterinary importance as parasites of ruminants, other mammals, and avian hosts. These nematodes are typically monoxenous and occur in the intestine or stomach of their terrestrial vertebrate hosts. Morphologically these taxa were originally defined by a reduced buccal capsule and distinctive copulatory bursa (Leiper, 1912;

Received 14 March 1994; revised 25 May 1994; accepted 25 May 1994.
Cram, 1927) and more recently by the configuration of the synlophe and characteristic genital structures (Durette-Desset and Chabaud, 1977, 1981; Durette-Desset, 1983; Gibbons and Khalil, 1982, 1983).

The family has received extensive attention since it was established, e.g., Yorke and Maplestone (1926), Baylis and Daubney (1926), and has been reviewed in detail by Travassos (1937), Skrjabin et al. (1952, 1954), Durette-Desset and Chabaud (1977, 1981), Gibbons and Khalil (1982) and Durette-Desset $(1983,1985)$. The first synoptic treatment of the family was presented by Travassos (1937) whose classification of the Trichostrongylidae contained 13 subfamilies. This represented a rather broad concept for the trichostrongylids and included many taxa later referred to other families and subfamilies of the Trichostrongyloidea (see Durette-Desset, 1983). More restrictive concepts for the trichostrongyloids were developed by Skrjabin et al. (1952, 1954) who recognized 15 subfamilies and 18 tribes within the Trichostrongylidae. The currently accepted taxonomy for the family followed from the first exhaustive studies of the genital cone and copulatory bursa (Andreeva, 1958; Chabaud, 1959; Chabaud et al., 1970; Gibbons and Khalil, 1983) and synlophe (Durette-Desset and Chabaud, 1977). Trichostrongylidae according to Durette-Desset and Chabaud $(1977,1981)$, Gibbons and Khalil (1982), and Durette-Desset (1983) is now considered to contain 6 subfami- 
lies including 4 economically significant groups: Trichostrongylinae Leiper, 1908, Ostertagiinae Lopez-Neyra, 1947, Haemonchinae Skrjabin and Shul'ts, 1952, Cooperiinae Skrjabin and Shikhobalova, 1952, and the relatively minor Libyostrongylinae Durette-Desset and Chabaud, 1977, and Graphidiinae Travassos, 1937.

Although Gibbons and Khalil (1982) and Durette-Desset (1983) both recognized 6 subfamilies, there was discordance between these classifications with respect to the numbers of genera recognized, particularly within the Ostertagiinae (see Lichtenfels and Hoberg, 1993) and to their placement at the level of subfamily. The apparent disparity resulted largely from conclusions derived from the evaluation of 2 different sets of morphological characters that were applied to the construction of taxonomic keys at the generic level. Concepts of Durette-Desset (1983) were based primarily on the structure of the copulatory bursa, whereas those of Gibbons and Khalil (1982) were based on a broader array of structural attributes (Lichtenfels, 1987).

Although all previous treatments of the trichostrongylids implied degrees of morphological similarity for inclusive groups of species, genera, tribes, and subfamilies, specific evolutionary hypotheses for the family were seldom considered. The first explicit evolutionary hypothesis for the 14 families of the Trichostrongyloidea, including the Trichostrongylidae, was presented as a dendrogram derived from the pioneering studies of Chabaud (1959), Durette-Desset and Chabaud (1977, 1981), and Durette-Desset $(1983,1985)$. Although Gibbons and Khalil (1982) had not intended to present a classification, their concepts were summarized by Lichtenfels (1987) in an attempt to define relationships among the subfamilies.

The competing hypotheses outlined by Lichtenfels (1987) represented 2 rather disparate views of evolution and postulated relationships among the 6 subfamilies. Durette-Desset $(1981,1983$, 1985) and Durette-Desset and Chabaud (1977, 1981) indicated that the Trichostrongylidae were divided into 3 lineages, depending on the morphology of bursal rays 2 and 3. Each of these lineages was further broken into subfamilies, 1 more primitive than the other. Other characters were then forced to conform to relationships defined by the structure of the bursa and thus extensive parallel trends in evolution were predicted by necessity (Durette-Desset, 1985, 1992). In contrast, the relationships derived by Lich- tenfels (1987) from the keys presented by Gibbons and Khalil (1982) considered a broader array of characters and 2 rather than 3 major lineages were recognized. An evaluation of these hypotheses revealed concepts of relationships among taxa that were developed from assessments of single characters, overall morphological similarity, or unique combinations of shared primitive characters. Although each of the subfamilies was recognized, the reliability of conclusions about phylogeny of the trichostrongylids and relationships among the subfamilies were equivocal (Jansen, 1989; Hoberg and Lichtenfels, 1992; Hoberg et al., 1993b).

In the present study, phylogenetic analyses (Hennig, 1966; Wiley, 1981) of the Trichostrongylidae were initiated to: (1) test monophyly of the family; (2) assess relationships among the subfamilies; (3) define the relationship of the Ostertagiinae and Graphidiinae (see Hoberg et al., 1993b); (4) consider the implications of subfamily phylogeny for trends in character evolution; and (5) begin preliminary assessments of host, habitat, and biogeographic associations of parasites. Results of this study provide the first phylogenetic systematic analysis of the Trichostrongylidae, as an extension of the seminal research of Chabaud (1959), Durette-Desset and Chabaud (1977, 1981), Gibbons and Khalil (1982), and Durette-Desset $(1983,1985,1992)$. In as much as systematics forms the foundation for predictive hypotheses, assessment of the phylogenetic relationships of the trichostrongylids at the subfamilial level can form the infrastructure for a more refined understanding of nematode behavior, parasite-host coevolution, and biogeography.

\section{MATERIALS AND METHODS}

Phylogenetic analysis (Hennig, 1966; Wiley, 1981; Wiley et al., 1991) of the subfamilies of the Trichostrongylidae was conducted based on an evaluation of morphological characters of adult nematodes. Representatives of all currently recognized subfamilies of the Trichostrongylidae were examined.

Characters were polarized by taxonomic outgroup comparison (Lundberg, 1972; Wiley, 1981; Wiley et al., 1991), with reference to the strongylate superfamilies Strongyloidea and Ancylostomatoidea and to other families of the Trichostrongyloidea. As the synlophe is an attribute limited to the Trichostrongyloidea, these characters were polarized specifically with reference to families Molineidae, Heligmosomidae, and Heligmonellidae. Selection of characters and argumentation for character state polarity were found to be primarily consistent with previous decisions developed by Chabaud et al. (1970), Durette-Desset and Chabaud (1977, 1981) 
TABLE I. Character matrix for the subfamilies of the Trichostrongylidae.

\begin{tabular}{|c|c|c|c|c|c|c|c|c|c|c|c|c|c|c|c|c|c|c|c|c|c|c|}
\hline \multirow[b]{2}{*}{ Subfamily } & \multicolumn{22}{|c|}{ Character } \\
\hline & 1 & 2 & 3 & 4 & 5 & 6 & 7 & 8 & 9 & $\begin{array}{l}1 \\
0\end{array}$ & $\begin{array}{l}1 \\
1\end{array}$ & $\begin{array}{l}1 \\
2\end{array}$ & 3 & $\begin{array}{l}1 \\
4\end{array}$ & $\begin{array}{l}1 \\
5\end{array}$ & $\begin{array}{l}1 \\
6\end{array}$ & 1 & $\begin{array}{l}1 \\
8\end{array}$ & 1 & $\begin{array}{l}2 \\
0\end{array}$ & $\begin{array}{l}2 \\
1\end{array}$ & $\begin{array}{l}2 \\
2\end{array}$ \\
\hline Strongylida* & 0 & 0 & 0 & 0 & 0 & 0 & 0 & 0 & 0 & 0 & 0 & 0 & 0 & 0 & 0 & 0 & 0 & 0 & 0 & 0 & 0 & 0 \\
\hline Trichostrongylinae & 2 & 0 & 1 & 1 & 0 & 0 & 1 & 1 & 0 & 1 & 0 & 1 & 0 & 0 & 0 & 0 & 0 & 0 & 0 & 1 & 0 & 0 \\
\hline Libyostrongylinae & 1 & 0 & 1 & 0 & 1 & 0 & 0 & 1 & 0 & 1 & 0 & 1 & 0 & 0 & 0 & 1 & 0 & 0 & 1 & 0 & 0 & 0 \\
\hline Haemonchinae & 0 & 1 & 0 & 0 & 1 & 1 & 0 & 0 & 1 & 0 & 0 & 0 & 0 & 0 & 0 & 0 & 1 & 1 & 0 & 1 & 1 & 1 \\
\hline Cooperiinae & 1 & 0 & 0 & 1 & 0 & 0 & 0 & 0 & 0 & 0 & 1 & 1 & 0 & 0 & 0 & 1 & 0 & 0 & 1 & 0 & 0 & 1 \\
\hline Ostertagiinae & 1 & 1 & 0 & 0 & 1 & 1 & 0 & 0 & 1 & 0 & 0 & 0 & 1 & 1 & 1 & 0 & 1 & 1 & 0 & 0 & 1 & 1 \\
\hline Graphidiinae & 0 & 1 & 0 & 0 & 0 & 1 & 0 & 0 & 1 & 0 & 1 & 0 & 0 & 0 & 0 & 0 & 0 & 1 & 0 & 0 & 0 & 0 \\
\hline
\end{tabular}

* Outgroups including the superfamilies Strongyloidea and Ancylostomatoidea and the families Molineidae, Heligmonellidae, and Heligmosomidae of the superfamily Trichostrongyloidea.

and Durette-Desset $(1983,1985)$, particularly for the synlophe and the bursa. Further refinement of definitions of characters was based on the literature with specific reference to Travassos (1937), Skrjabin et al. (1952, 1954), Sarwar (1956), Andreeva (1958), Lichtenfels (1977), Durette-Desset (1982a) for Cooperiinae, Durette-Desset (1982b) for Ostertagiinae, Gibbons and Khalil (1982, 1983), Gibbons (1981), Hoberg and Lichtenfels (1992), and Hoberg et al. (1993b, 1993c).

Some characters were found to be variable within in-group taxa. In such cases where both the plesiomorphic and apomorphic condition were present, given characters were coded as apomorphic for the subfamily to recognize the acquisition of the derived state in at least some of the in-group genera. This decision influenced coding for 7 characters as follows (with derived state listed first): buccal tooth (character 5-Libyostrongylinae with presence or absence of this attribute); form of the bursa (character 12-Cooperiinae with both 1-3-1 and 2-3; character 13-Ostertagiinae with both 2-2-1 and 2-1-2); dorsal lobe (character 17-Ostertagiinae with reduced and long dorsal lobe); spicule length (character 18-Ostertagiinae and the Haemonchinae with long and short spicules); dorsal ray symmetry (character 21 -Ostertagiinae and Haemonchinae with asymmetric and symmetric dorsal lobes); vulval flap (character 22-Cooperiinae, Ostertagiinae, and Haemonchinae, presence or absence of flaps). Potential influence on the topology of cladogram(s) due to these decisions for coding of variable characters was examined with an alternate matrix in which character states as presented above were coded as plesiomorphic.

Five multistate characters were split into independent transformation series and recoded as binary characters (see Glen and Brooks, 1985) to account for derivation of some character states as follows: cephalic vesicle (characters 2,3$)$, synlophe, number of ridges $(9$, $10)$, bursa form $(12,13)$, " 7 " papillae $(15,16)$, and bursal rays 2 and $3(19,20)$.

A summary of the 22 homologous series, representing 23 character states, is presented below and in a numerical character matrix (Table I). Plesiomorphic states are coded as 0 , apomorphic as 1 or 2 . Characters have been illustrated to depict the plesiomorphic and apomorphic state for each attribute (Figs. 1-14).

Phylogenetic analysis was conducted with PAUP version 2.4 (Swofford, 1985). The following options were used: ALLTREES, FARRIS OPTIMIZATION, with multistate characters ordered. The consistency index (CI) was calculated for individual characters and for the overall analysis. Calculation of the homoplasy slope ratio (HSR) and $\mathrm{CI}_{\text {random }}$ and $\mathrm{CI}_{\text {adjusted }}$ followed Meier et al. (1991) and Klassen et al. (1991). Comparisons to previous hypotheses (specifically those of Durette-Desset and Chabaud [1981], Durette-Desset [1985], and Lichtenfels [1987] were based on the USER DEFINED TOPOLOGY function of PAUP. The dendrograms for the Trichostrongylidae developed by Durette-Desset and Chabaud (1981) and Lichtenfels (1987), the latter based on Gibbons and Khalil (1982), were redrawn and employed as USER DEFINED TREES to compare these alternative hypotheses directly. Characters used in the current analysis were mapped onto these trees and optimized by FARRIS OPTIMIZATION. The overall $\mathrm{CI}$ and those for individual characters were calculated, and the HSR and $\mathrm{CI}_{\text {adjusted }}$ were determined as a basis for evaluating the efficiency and strength of the competing hypotheses for trichostrongylid phylogeny.

Host habitat (localization in the host), host associations, and geographic distributions of subfamilial taxa were examined by mapping these data onto the parasite phylogeny produced in the current study.

\section{RESULTS}

\section{Characters}

1) Body length of male. Three states: $0=$ relatively long (consistently $>10 \mathrm{~mm}$ ) $11=$ medium in length (generally 6-10 $\mathrm{mm}$ ); $2=$ minuscule (typically $<5 \mathrm{~mm}$ ).

2, 3) Cephalic vesicle (presence and structure) (Fig. 1). The structure of the cephalic vesicle is variable within the Trichostrongylidae and was split into 2 independent transformation series (see Glen and Brooks, 1985). It is represented by a well-developed large cephalic and cervical expansion demarcated from the body in the Cooperiinae (and most outgroups) $(0,0)$ (Fig. 1a). A reduced, poorly developed cephalic and cervical expansion is characteristic of the Ostertagiinae, Graphidiinae, and Haemonchinae $(1,0)$ (Fig. 1b), whereas cephalic modification is absent in the 
Trichostrongylinae and Libyostrongylinae $(0,1)$ (Fig. 1c). Character 2. Two states: $0=$ well developed; $1=$ reduced. Character 3 . Two states: $0=$ well developed; $\mathrm{I}=$ absent.

4) Buccal cavity (Fig. 2). Two states: $0=$ present; 1 = present, poorly developed.

5) Buccal tooth (Fig. 3). Two states: $0=$ absent; 1 = present (considered to include the "neodont" of Durette-Desset, 1985).

6) Cervical papillae (form) (Fig. 4). Two states: $0=$ sensilla-like, often situated in a pit; $1=$ large, thornlike, often triangular, projecting from body surface.

7) Excretory pore (Fig. 5). Two states: $0=$ aperture not contained in a depression of the body surface; 1 = aperture situated in permanent $\mathrm{v}$-shaped depression.

8) Synlophe (presence and development) (Fig. 6). Two states: $0=$ present and extending into posterior region of the body; 1 = reduced, limited to specific regions of the cuticle (usually near the vulva) or absent.

9, 10) Synlophe (number of ridges) (Fig. 7). Split into independent series, the synlophe may be composed of relatively few ridges as in the Cooperiinae $(0,0)$ (Fig. 7a), may be composed of a high number of ridges as in the Haemonchinae, Ostertagiinae, and Graphidiinae $(0,1)$ (Fig. 7b), or may be reduced or absent as in the Libyostrongylinae and Trichostrongylinae $(1,0)$ (Fig. 7c). Character 9. Two states: $0=$ low number; 1 = high number. Character 10 . Two states: $0=$ low number; $1=$ absent or reduced.

11) Synlophe (ridge height). Two states: $0=$ ridges of near equal height; $1=$ lateral ridges or lateralmost ridge substantially smaller than those in the dorsal and ventral fields.

12, 13) Bursa (form and type) (Fig. 8). Among outgroups, the bursa may be $2-1-2$ or 2-3 (e.g., Strongyloidea and Molineidae); derived states are represented by 1-3-1 (Trichostrongylinae, Libyostrongylinae, and Cooperiinae with a limited number of genera of the latter with 2-3) or 2-2-1 (Ostertagiinae and only among a limited number of heligmosomes). This multistate character was split to recognize the potential of independent origin of derived states for the form of the bursa: the bursa may be $2-3$ or $2-1-2(0,0)$ (Fig. $8 \mathrm{a}, \mathrm{b}$ ), 1-3-1 $(1,0)$ (Fig. 8c), or 2-2-1 $(0,1)$ (Fig. 8d). Character 12. Two states: $0=2-3$ or $2-1-2 ; 1=$ 1-3-1. Character 13. Two states: $0=2-3$ or $2-1$ $2 ; 1=2-2-1$.

14) Ventral raylet or "0" papilla (structure) (Fig. 9). Two states: $0=$ single papilla (Fig. 9a, b); 1 = paired papillae (Fig. 9c) (see Hoberg et al. [1993b] regarding detailed argumentation for this character).

$15,16)$ Dorsal raylets or " 7 " papillae and the accessory bursal membrane (Fig. 9). Split into independent transformation series, the "7" papillae may be papilliform with a reduced membrane $(0,0)$ (Fig. 9a), elongate and well-developed supporting a prominent accessory bursal membrane $(1,0)$ (Fig. 9c), or with a highly modified membrane $(0,1)$ (Fig. 9d). Character 15. Two states: $0=$ papilliform with a reduced or modified membrane; 1 = elongate with a highly developed membrane. Character 16. Two states: $0=$ papilliform and reduced or elongate; $1=$ modified.

17) Dorsal lobe of bursa and dorsal ray (Fig. 10). Two states: $0=$ long dorsal lobe and ray; 1 $=$ reduced or short dorsal lobe and ray.

18) Spicules (relative length). Two states: $0=$ short; 1 = long.

19, 20) Bursal rays 2 and 3 (relative length and position) (Fig. 12). Split into independent transformation series, the tips of rays 2 and 3 may be equal in length and parallel $(0,0)$ (Fig. 12a), ray 2 may be less in length than ray 3 with the tips being convergent $(1,0)$ (Fig. 12c), or ray 2 may be shorter than ray 3 with the tips being divergent $(0,1)$ (Fig. 12b). Character 19. Two states: $0=$ equal and parallel; $1=$ convergent. Character 20 . Two states: $0=$ equal; 1 = divergent.

21) Dorsal ray (symmetry) (Fig. 10). $0=$ symmetric dorsal ray; $1=$ asymmetric dorsal ray.

22) Vulval flap (presence) (Fig. 11). $0=$ absent; $1=$ present.

\section{Phylogenetic analysis}

A single phylogenetic tree for the relationships of the 6 subfamilies of the Trichostrongylidae resulted from the analysis of 22 morphological attributes (represented by 23 character states) (Fig. 15). The hypothesis was strongly supported with a CI $=74.2 \%$ (minimum length $=23$ steps; postulated steps $=31), \mathrm{HSR}=51.3 \%$, and $\mathrm{CI}_{\text {adjusted }}$ $=19.2 \%\left(\mathrm{CI}_{\text {actual }}-\mathrm{CI}_{\text {random }}=\mathrm{CI}_{\text {adjusted }}\right)$, indicating substantial phylogenetic information was contained in the cladogram. Consistency indices for individual characters are present in Table II. Homoplasy was postulated for parallel development in 5 characters (body length, buccal tooth, synlophe height, bursal rays 2 and 3 , and vulval flap) and reversal in 3 characters (buccal cavity, "7" papillae and bursal rays 2 and 3). Postulated instances of homoplasy were evenly distributed 

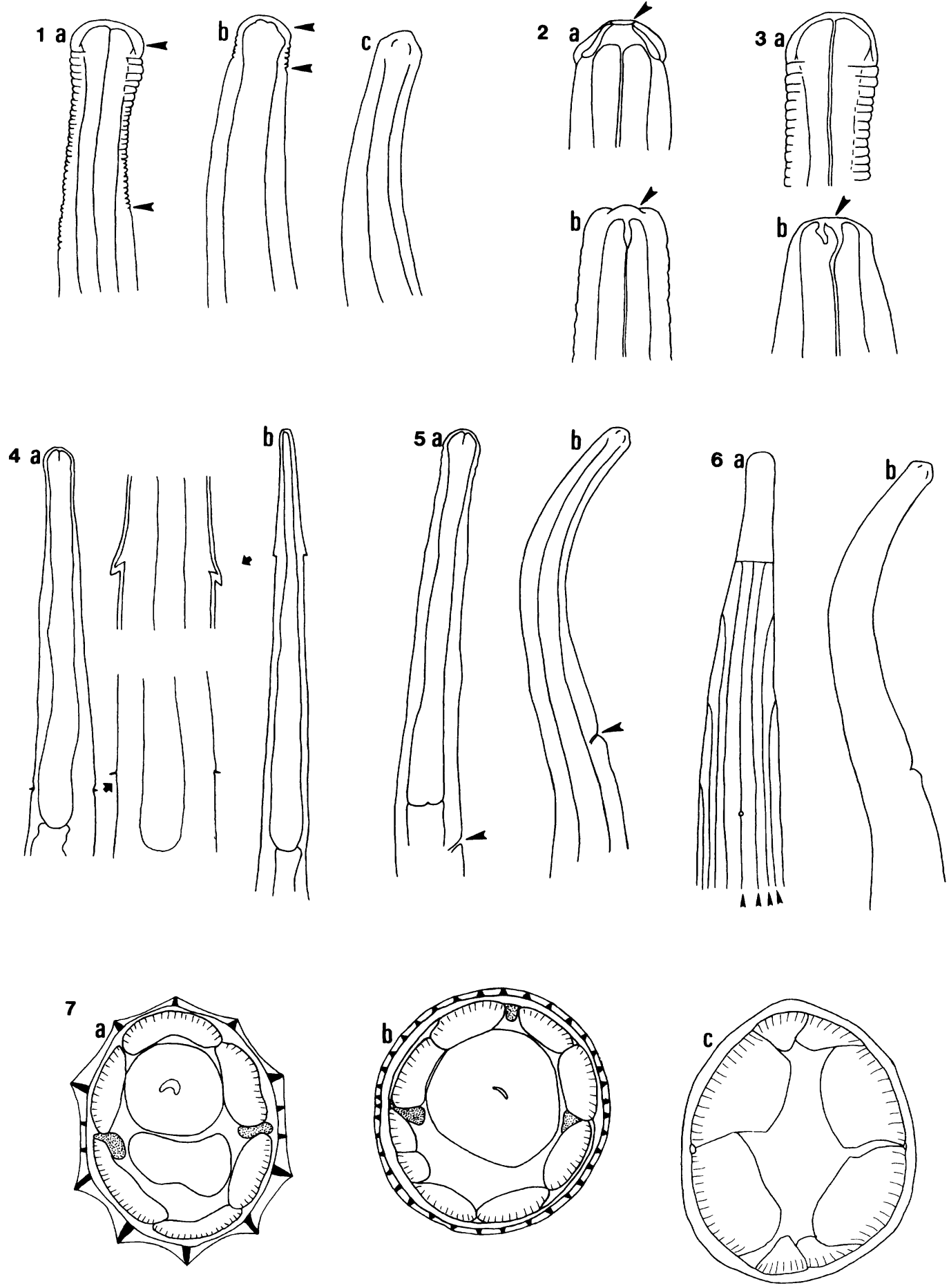

FIGURES 1-7. Characters used in phylogenetic analysis of the subfamilies of the Trichostrongylidae (not to scale). In each figure, the plesiomorphic condition is indicated by "a" and the apomorphic condition by " $b$," "c," etc. 1. Cephalic vesicle, denoted by region between pointers (characters 2/3): 1a. Large vesicle in Cooperia curticei (Giles, 1892) (from Gibbons and Khalil, 1982). 1b. Reduced vesicle in Longistrongylus namaquensis (Ortlepp, 1963) (from Gibbons, 1977). 1c. Absence of vesicle in Trichostrongylus colubriformis (Giles, 1892) (from Gibbons and Khalil, 1982). 2. Buccal cavity, indicated by pointer (character 4): 2a. Present and developed 
through the tree and largely restricted to terminal taxa and branches.

Monophyly for the Trichostrongylidae is supported by 2 synapomorphies (defined by reference to taxonomic outgroups): the length of ray 4 of the copulatory bursa (Fig. 13) and the absence (putative secondary loss) of the tail spine in the female (Fig. 14), both largely consistent characters that were excluded from the analysis. With respect to a long ray 4 , this attribute is present among all subfamilies, although in a limited number of the Ostertagiinae this ray is short (e.g., Spiculopteragia [Orloff, 1933], Mazamastrongylus Cameron, 1935, Rinadia Grigorian, 1951, and Apteragia Jansen, 1958). Thus, with the presence of both apomorphic and plesiomorphic states for this character in the Ostertagiinae (and coding as apomorphic for the genus), the character may be interpreted as undergoing a reversal among a limited number of genera in this taxon. This is compatible with a secondary reduction in the length of the 4th ray, whereas all other genera of the Ostertagiinae (see Gibbons and Khalil 1982; Durette-Desset 1983, 1989; Jansen, 1989) have the synapomorphic condition that defines the family Trichostrongylidae.

Two major clades sharing a sister-group relationship were recognized within the Trichostrongylidae (Fig. 15). The Cooperiinae clade (the basal Cooperiinae and the Libyostrongylinae + Trichostrongylinae) and the Graphidiinae clade (the basal Graphidiinae and the Ostertagiinae + Haemonchinae) were each defined by 4 synapomorphies. Considering the Cooperiinae clade, a 1-3-1 bursa (character 12) unequivocally defines this inclusive group. Additionally, the absence of a buccal cavity (4), a modified accessory bursal membrane and "7" papillae (16), and convergence of ray 2 and 3 (19) are generally constant within the clade but undergo postulated reversal in the Libyostrongylinae (4) and the Trichostrongylinae $(16,19)$. The sister-group association within the Cooperiinae clade of the Libyostrongylinae + Trichostrongylinae is supported by 3 synapomorphies: absence of a cephalic vesicle (3) and reduction or absence of the synlophe (8, 10).

In contrast, the Graphidiinae clade is defined by a reduced cephalic vesicle (character 2 ), thornlike cervical papillae (6), a high number of ridges comprising the synlophe (9), and relatively long spicules (18). The sister-group relationship within the Graphidiinae clade of the Ostertagiinae + Haemonchinae is supported by 2 synapomorphies: reduced dorsal lobe (17), asymmetric dorsal ray (21), and secondarily by the presence of a buccal tooth (5) and vulval flap (22).

A minimal level of parallelism in 5 characters is evident and distributed across both clades (Fig. $15)$. The medium length of the body (1) is found in the Cooperiinae and Libyostrongylinae of the Cooperiinae clade and the Ostertagiinae of the Graphidiinae clade. A buccal tooth (5) is present in some Libyostrongylinae and the Haemonchinae + Ostertagiinae. A reduction in the height of the lateralmost ridge (11) is evident in the Cooperiinae and the Graphidiinae. Bursal rays 2 and 3 are divergent (20) in the Trichostrongylinae and the Haemonchinae. Vulval flaps (22) are present in the Ostertagiinae + Haemonchinae and the Cooperiinae.

The influence of differences in coding for variable characters was examined. An alternate matrix with these specific characters coded as plesiomorphic (5 for Libyostrongylinae; 12,22 , for Cooperiinae; 13, 17, for Ostertagiinae; and 18, 21,22 , for Haemonchinae and the Ostertagiinae) was analyzed. A single tree resulted with a $\mathrm{CI}=$ $76.9 \%$; there were no changes in the overall to-

\footnotetext{
in Ostertagia ostertagi (Stiles, 1892) (from Andreeva, 1958). 2b. Poorly developed in Trichostrongylus retortaeformis (Zeder, 1800) (from Yorke and Maplestone, 1926). 3. Buccal tooth indicated by pointer (character 5): 3a. Absence of tooth in Cooperia fuelleborni Hung, 1926 (from Gibbons, 1981). 3b. Presence of tooth in Haemonchus contortus (Rudolphi, 1802) (from Gibbons and Khalil, 1982). 4. Cervical papillae in dorsoventral view, showing relative position in cervical region and structure (arrows) (character 6): 4a. Sensilla-like papillae in Cooperia sp. (from Gibbons, 1981). 4b. Thornlike papillae in Haemonchus contortus (from Gibbons, 1979). 5. Excretory pore in lateral view (pointers) (character 7): 5a. Unmodified pore in Cooperia fuelleborni (from Gibbons, 1981). 5b. Pore in v-shaped notch in T. colubriformis (from Gibbons and Khalil, 1982). 6. Synlophe (character 8): 6a. Cervical region, showing ventral view and ridges (pointers) in Cooperia neitzi Monnig, 1932 (from Hoberg et al., 1993c). 6b. Absence of synlophe in T. colubriformis (from Gibbons and Khalil, 1982). 7. Synlophe in transverse section near midbody (characters 9/10): 7a. Low numbers of ridges in $C$. curticei (from Gibbons, 1981). 7b. High number of ridges in $O$. ostertagi (from Gibbons and Khalil, 1982). 7c. Reduction of synlophe in Libyostrongylus douglassi (Cobbold, 1882) (from Gibbons and Khalil, 1982).
} 
8
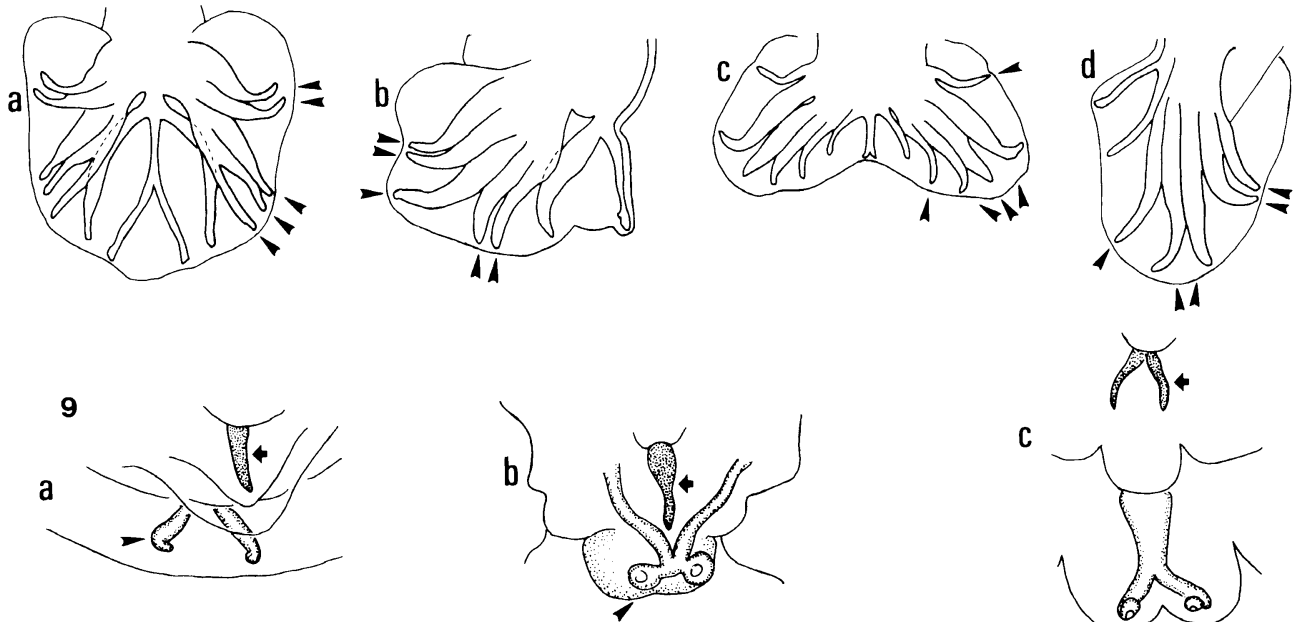

C
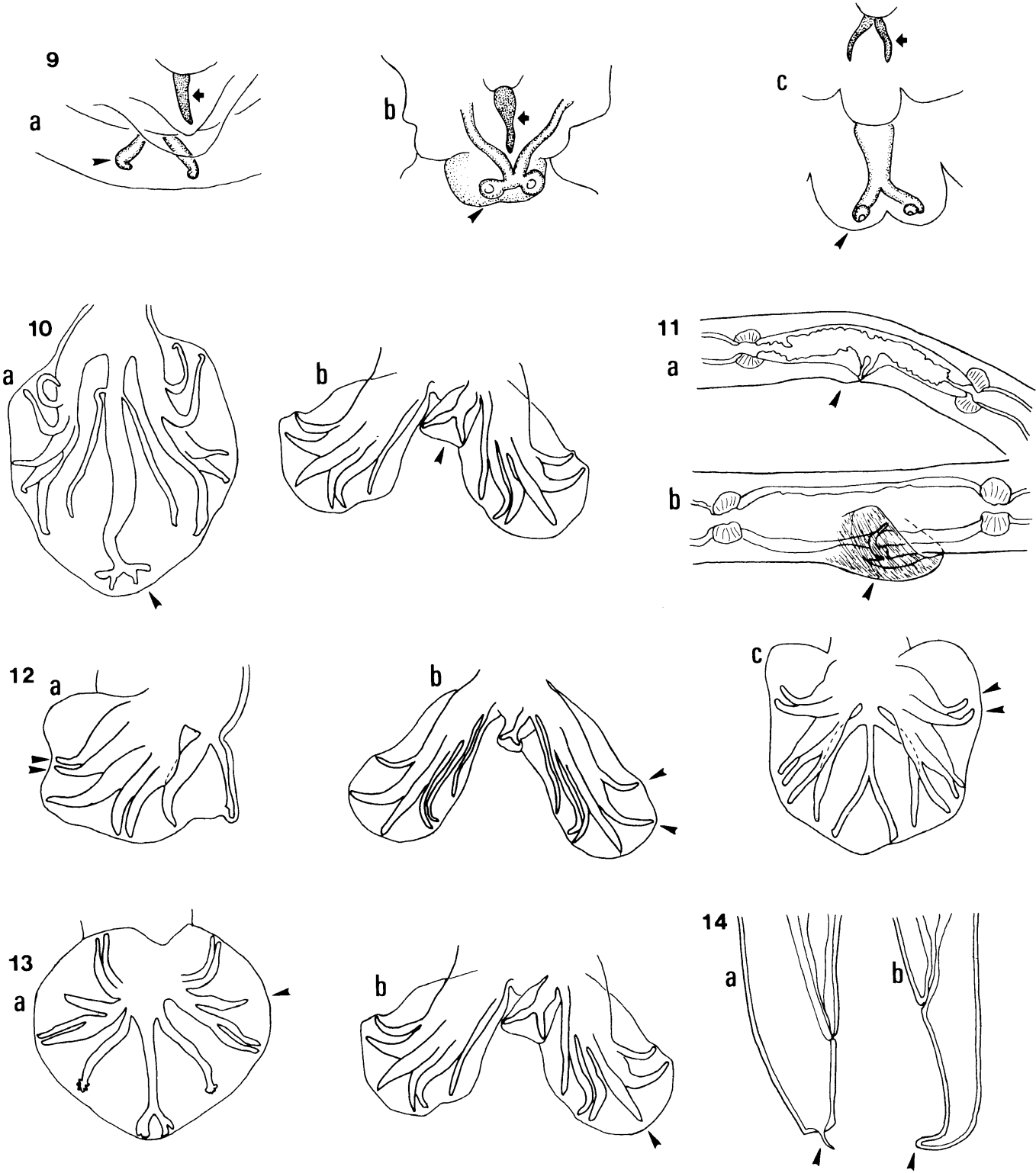

FIGURES 8-14. Characters used in phylogenetic analysis of the subfamilies of the Trichostrongylidae (not to scale). In each figure, the plesiomorphic condition is indicated by "a," and the apomorphic condition by " $b$," "c," etc. 8. Bursa form with disposition of rays indicated by pointers (characters 12/13): 8a. A 2-3 bursa in Cooperioides kenyensis Daubney, 1933 (from Durette-Desset, 1983). 8b. A 2-1-2 bursa in Ostertagia spp. (from Andreeva, 1958). 8c. A 1-3-1 bursa in T. retortaeformis (from Skrjabin et al., 1954). 8d. A 2-2-1 bursa in Teladorsagia spp. (from Andreeva, 1958). 9. Structure of "0" (arrows) and "7" (pointers) papillae in ventral 
pology, relationships, or support of nodes and terminal branches of the tree. However, 3 characters became constant $(13,21,22)$, reducing the number of phylogenetically informative characters in the analysis to 19.

\section{Alternate hypotheses for the Trichostrongylidae}

Explicit dendrograms for the relationships of the trichostrongylids, as presented in the literature, were redrawn as cladograms to promote their evaluation with respect to the present phylogeny using the TOPOLOGY function of PAUP (Swofford, 1985). Characters from the current study were mapped onto these alternative trees and optimized to allow a determination of the efficiency of each of the competing hypotheses. The forced topological comparison (including the $\mathrm{CI}$, HSR, and $\mathrm{CI}_{\text {adjusted }}$ ), based on a single character database, emphasizes putative differences in character evolution and relative support for relationships at the level of subfamilies within the Trichostrongylidae.

The hypothesis developed by Durette-Desset and Chabaud (1981) and Durette-Desset (1983, 1985) specifies sister-group relationships for 3 distinct lineages (Cooperiinae + Libyostrongylinae; Graphidiinae + Ostertagiinae; and Trichostrongylinae + Haemonchinae) (Fig. 16). The resulting cladogram (as a user-defined topology) had a $\mathrm{CI}=56.1 \%$ (minimum length $=23$; steps required $=41) ; \mathrm{HSR}=1.0$ and $\mathrm{CI}_{\text {adjusted }}=1.1 \%$, indicating minimal phylogenetic information was contained in the hypothesis. Homoplasy was postulated for 15 characters with parallel development in 10 attributes and 5 instances of re-
TABLE II. Consistency indices for individual characters used in analysis of the Trichostrongylidae.

\begin{tabular}{llll}
\hline $\begin{array}{c}\text { Char- } \\
\text { acter } \\
\text { num- } \\
\text { ber }\end{array}$ & \multicolumn{1}{c}{ Character } & CI & Homoplasy* \\
\hline 1 & Body length & 0.667 & $\mathrm{P}$ \\
2 & Cephalic vesicle & 1.0 & - \\
3 & Cephalic vesicle & 1.0 & - \\
4 & Buccal cavity & 0.50 & $\mathrm{R}$ \\
5 & Buccal tooth & 0.50 & $\mathrm{P}$ \\
6 & Cervical papillae & 1.0 & - \\
7 & Excretory pore & 1.0 & - \\
8 & Synlophe (presence) & 1.0 & - \\
9 & Synlophe (no. of ridges) & 1.0 & - \\
10 & Synlophe (no. of ridges) & 1.0 & - \\
11 & Synlophe (height) & 0.50 & $\mathrm{P}$ \\
12 & Bursa (form) & 1.0 & - \\
13 & Bursa (form) & 1.0 & - \\
14 & “0” Papilla(e) & 1.0 & - \\
15 & “7” Papillae & 1.0 & - \\
16 & “7” Papillae & 0.50 & $\mathrm{R}$ \\
17 & Dorsal ray (development) & 1.0 & - \\
18 & Spicules (length) & 1.0 & - \\
19 & Bursa (rays 2, 3) & 0.50 & $\mathrm{R}$ \\
20 & Bursa (rays 2, 3) & 0.50 & $\mathrm{P}$ \\
21 & Dorsal ray (symmetry) & 1.0 & - \\
22 & Vulval flap & 0.50 & $\mathrm{P}$ \\
\hline
\end{tabular}

* Postulated homoplasy as indicated by: $\mathrm{P}=$ parallelism; $\mathrm{R}=$ reversal.

versal being required to describe relationships depicted in the tree (Table III).

Monophyly was assumed for the Trichostrongylidae, but support for sister-group relationships was minimal. The Cooperiinae + Libyostrongylinae are defined by 2 synapomorphies (character 16, dorsal raylets; 19 , bursal rays 2 and 3). The Graphidiinae + Ostertagiinae and Trichostrongylinae + Haemonchinae are defined by 4 characters (character 2, cephalic ves-

view (characters 14, 15, 16): 9a. Single " 0 " papilla and reduced "7" and membrane in T. colubriformis (from Gibbons and Khalil, 1982). 9b. Single " 0 " papilla and highly modified " 7 " and membrane in Cooperia rotundispiculum Gibbons and Khalil, 1980 (from Gibbons, 1981). 9c. Paired " 0 " papilla and elongate " 7 " papillae with accessory bursal membrane Camelostrongylus mentulatus (Railliet and Henry, 1909) (from Gibbons and Khalil, 1982). 10. Structure of dorsal lobe and ray (characters 17 and 21): 10a. Long, symmetric dorsal ray and lobe in ventral view in Cooperia pectinata Ransom, 1907 (from Gibbons and Khalil, 1982). 10b. Short, asymmetric dorsal ray and lobe in dorsal view in $H$. contortus (from Gibbons and Khalil, 1982). 11. Vulval flap seen in left lateral view (character 22): 11a. Absence of flap in Cooperia connochaetes Boomker, Horak and Alves, 1979 (from Gibbons, 1981). 11b. Presence of flap in Teladorsagia circumcincta (Stadleman, 1894) (from Lancaster and Hong, 1990). 12. Bursal rays 2 and 3 showing length and disposition of tips as indicated by pointers (characters 19/20): 12a. Rays equal and parallel in Ostertagia spp. (from Andreeva, 1958). 12b. Ray $2<3$ and divergent in Haemonchus longistipes Railliet and Henry, 1909 (from Gibbons, 1979). 12c. Ray $2<3$ and convergent in $C$. kenyensis (from Durette-Desset, 1983). 13. An elongate bursal ray 4 (pointers) is a putative synapomorphy for the Trichostrongylidae: 13a. Short ray in Amphibiophilus chabaudi Skrjabin, 1916 (from Durette-Desset, 1983). 13b. Long ray 4 in $H$. contortus (from Gibbons and Khalil, 1982). 14. A rounded tail in females (pointers) is a putative synapomorphy for the Trichostrongylidae: 14a. Tail with spine in Nematodirus archari Sokolova, 1948 (from Rickard and Lichtenfels, 1989). 14b. Rounded tail without spine in Parostertagia heterospiculum Schwartz and Alicata, 1933 (from Gibbons and Khalil, 1982). 


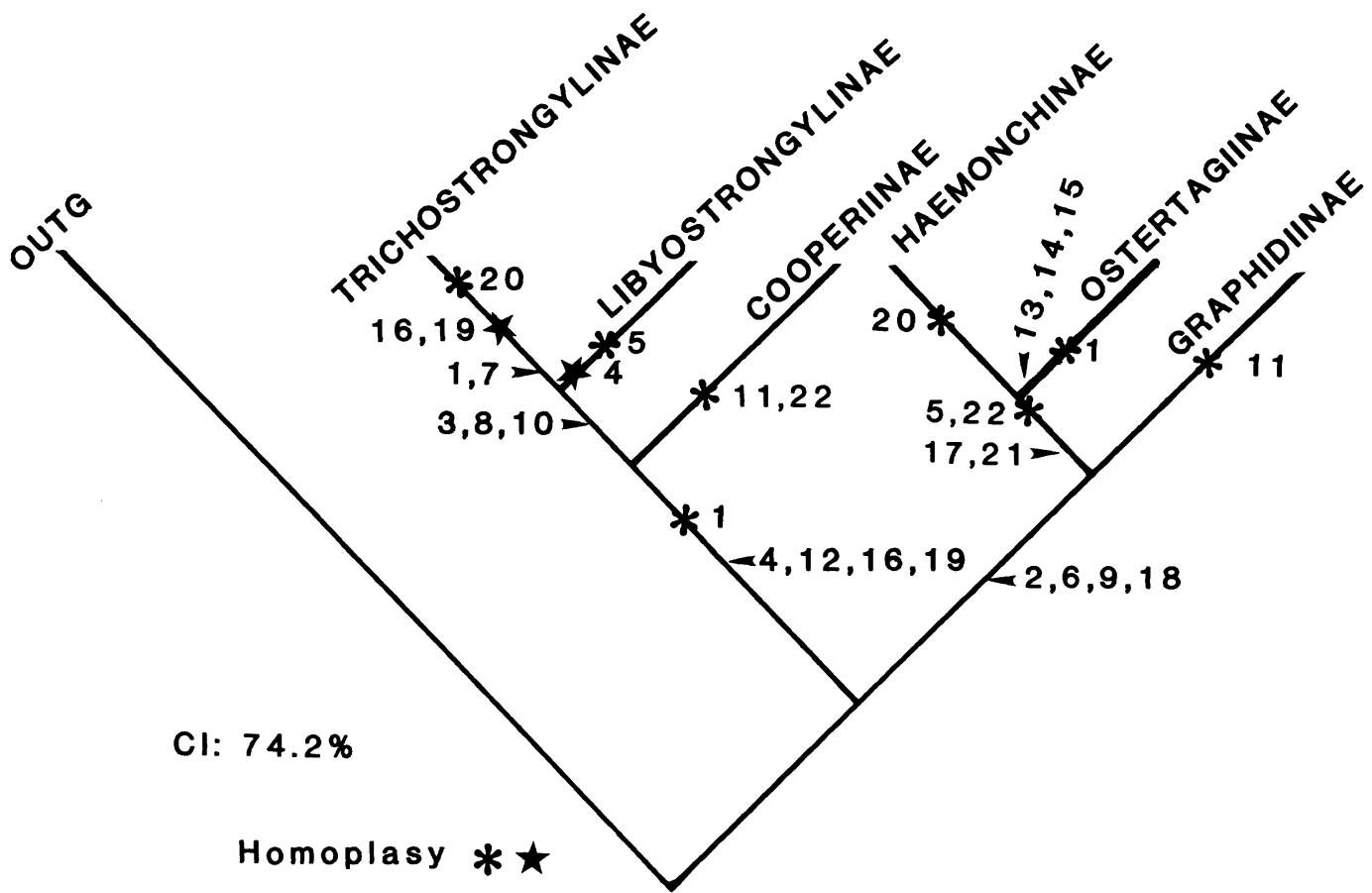

FIGURE 15. Cladogram derived from the analysis presented in the current study showing phylogenetic hypothesis for the 6 subfamilies of the Trichostrongylidae. This hypothesis has a CI $=74.2 \%, \mathrm{CI}_{\text {adjusted }}=19.2 \%$ and HSR $=51.3 \%$, indicating strong support for the hypothesis. Two major clades are recognized: the Cooperiinae clade comprised of Cooperiinae, Libyostrongylinae, and Trichostrongylinae and the Graphidiinae clade with Graphidiinae, Ostertagiinae, and Haemonchinae. Characters have been mapped onto the tree, and apomorphic attributes are noted by arrows defining specific nodes and branches, whereas postulated homoplasy is indicated by asterisks (parallelism and convergence) and stars (reversals); numbering is consistent with the data matrix, and definitions of characters are presented in the text.

icle; 6 , cervical papillae; 9 , synlophe; 18 , spicules) that undergo reversal in the Trichostrongylinae. A synapomorphy supporting the Ostertagiinae + Graphidiinae is lacking and the Haemonchinae + Trichostrongylinae are defined by a single attribute (20, bursal rays 2 and 3 ). Absence of unequivocal support for the hypothesis is indicated by a high level of homoplasy in the terminal branches, a high HSR, and low $\mathrm{CI}_{\text {adjusted }}$ (Fig. 16).

Parallelism was not evenly distributed but was associated with terminal branches (taxa) in each of the 3 lineages. Specifically most instances of parallel development occurred between the Ostertagiinae and Haemonchinae (4 characters: character 5, buccal tooth; 17 , dorsal lobe; 21 , dorsal ray; and 22, vulval flap) and the Trichostrongylinae and the Libyostrongylinae + Cooperiinae ( 5 characters: 3 , cephalic vesicle; 4 , buccal cavity; 8 , synlophe; and 10, synlophe).
The hypothesis developed by Lichtenfels (1987) was based on morphological studies conducted by Gibbons and Khalil (1982), which resulted in the development of a key for the family. This hypothesis specifies sister-group relationships for 2 distinct lineages (Trichostrongylinae + Libyostrongylinae and Haemonchinae as the sistergroup of the Graphidiinae + Ostertagiinae + Cooperiinae) (Fig. 17). The resulting cladogram (as a user-defined topology) had a $\mathrm{CI}=59.0 \%$ (minimum length $=23$; steps required $=39$ ); $\mathrm{HSR}=95.7 \%$ and $\mathrm{CI}_{\text {adjusted }}=4.0 \%$, indicating minimal phylogenetic information was contained in the hypothesis. Homoplasy was postulated for 15 characters with parallel development in 9 attributes and 6 instances of reversal being required to describe relationships depicted in the tree (Table IV).

Monophyly was assumed for the Trichostrongylidae, but support for sister-group relation- 


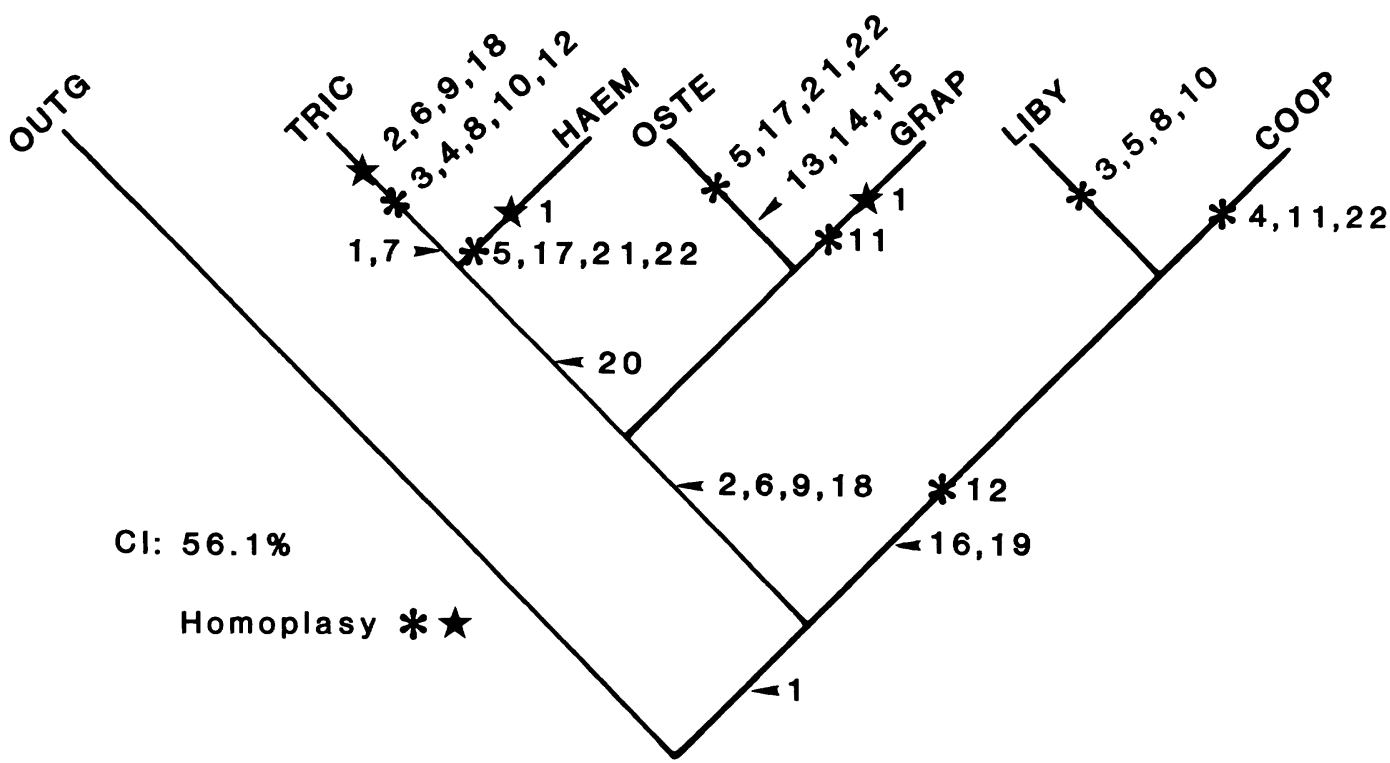

FIGURE 16. Cladogram for the Trichostrongylidae based on the dendrogram presented by Chabaud and Durette-Desset (1977) and Durette-Desset $(1983,1985,1992)$. The tree represents a user-defined topology and allows direct comparison to the present analysis (Fig. 15). This hypothesis has a $\mathrm{CI}=56.1 \%, \mathrm{CI}_{\text {adjusted }}=1.1 \%$, and HSR $=1.0$, indicating that minimal phylogenetic information is presented. The distribution of putative apomorphic attributes is indicated by arrows, and homoplasy is represented by asterisks (parallelism and convergence) or stars (reversal); numbering of characters is consistent with the data matrix and definitions presented in the text. Terminal branches are as follows: COOP $=$ Cooperiinae, LIBY $=$ Libyostrongylinae, GRAP $=$ Graphidiinae, OSTE $=$ Ostertagiinae, HAEM $=$ Haemonchinae, and TRIC $=$ Trichostrongylinae.

ships was minimal. The Trichostrongylinae + Libyostrongylinae are defined by 3 synapomorphies (character 3, cephalic vesicle; and 8 and 10 , synlophe). The Haemonchinae clade is defined by 5 characters (character 2, cephalic vesicle; 6 , cervical papillae; 9 , synlophe; 18 , spicules; 22 , vulval flap) that undergo reversal in the Cooperiinae or Graphidiinae. A synapomorphy supports the Graphidiinae + Ostertagiinae and Cooperiinae (11, synlophe). Absence of unequivocal support for the hypothesis is indicated by a low $\mathrm{CI}_{\text {adjusted }}$, a high HSR, and a high level of homoplasy in the terminal branches.

Homoplasy was not evenly distributed among taxa (Fig. 17). Specifically, most instances of parallel development occurred between the Ostertagiinae and Haemonchinae ( 3 characters: character 5 , buccal tooth; 17 , dorsal lobe; 21 , dorsal ray) and the Cooperiinae with the Trichostrongylinae and the Libyostrongylinae (4 characters: 4, buccal cavity; 12 , bursa; 16 , "7" papillae; 19 , bursa). Among characters with postulated reversal, 4 of 6 were associated with the Cooperiinae
TABLE III. Consistency indices for individual characters used in analysis of Trichostrongylidae when applied to the hypothesis of Durette-Desset (1985).

\begin{tabular}{cll}
\hline $\begin{array}{c}\text { Character } \\
\text { number }\end{array}$ & CI & Homoplasy* \\
\hline 1 & 0.50 & $\mathbf{R}$ \\
2 & 0.50 & $\mathbf{R}$ \\
3 & 0.50 & $\mathbf{P}$ \\
4 & 0.50 & $\mathbf{P}$ \\
5 & 0.333 & $\mathbf{P}$ \\
6 & 0.50 & $\mathbf{R}$ \\
7 & 1.0 & - \\
8 & 0.50 & $\mathbf{P}$ \\
9 & 0.50 & $\mathbf{R}$ \\
10 & 0.50 & $\mathbf{P}$ \\
11 & 0.50 & $\mathbf{P}$ \\
12 & 0.50 & $\mathbf{P}$ \\
13 & 1.0 & - \\
14 & 1.0 & - \\
15 & 1.0 & - \\
16 & 1.0 & - \\
17 & 0.50 & $\mathbf{P}$ \\
18 & 0.50 & $\mathbf{R}$ \\
19 & 1.0 & - \\
20 & 1.0 & - \\
21 & 0.50 & $\mathbf{P}$ \\
22 & 0.333 & $\mathbf{R}$ \\
\hline
\end{tabular}

* Postulated homoplasy as indicated by: $P$ = parallelism; $R=$ reversal. 


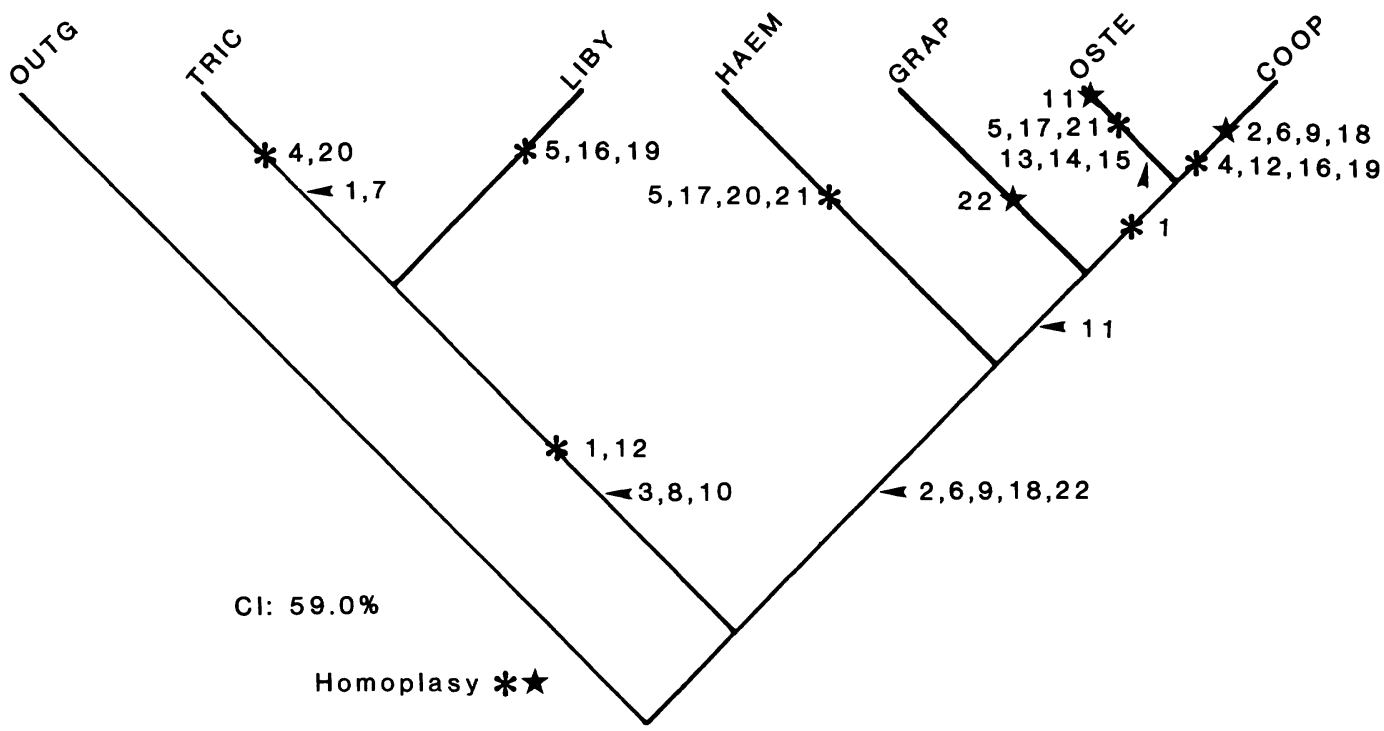

FIGURE 17. Cladogram for the Trichostrongylidae based on the dendrogram presented by Lichtenfels (1987) from studies by Gibbons and Khalil (1982). The tree represents a user-defined topology, allowing direct comparison to competing hypotheses (Figs. 15,16 ). The hypothesis has a $\mathrm{CI}=59.0 \%, \mathrm{CI}_{\text {adjusted }}=4.0 \%$, and $\mathrm{HSR}$ $=95.7 \%$, indicating minimal phylogenetic information is presented and that putative relationships are not well supported. The distribution of putative apomorphic characters is indicated by arrows, and homoplasy is represented by asterisks (parallelism and convergence) or stars (reversal). Characters are consistent with those presented in the data matrix and are defined in the text. Terminal branches are as follows: TRIC $=$ Trichostrongylinae, $\mathrm{LIBY}=$ Libyostrongylinae, HAEM $=$ Haemonchinae, GRAP $=$ Graphidiinae, OSTE $=$ Ostertagiinae, and COOP $=$ Cooperiinae.

TABLE IV. Consistency indices for individual characters used in analysis of Trichostrongylidae when applied to the dendrograms presented by Lichtenfels (1987) based on a key to genera of the Trichostrongylidae by Gibbons and Khalil (1982).

\begin{tabular}{|c|c|c|}
\hline $\begin{array}{l}\text { Character } \\
\text { number }\end{array}$ & $\mathrm{CI}$ & Homoplasy* \\
\hline 1 & 0.667 & $\mathbf{P}$ \\
\hline 2 & 0.50 & $\mathbf{R}$ \\
\hline 3 & 1.0 & - \\
\hline 4 & 0.50 & $\mathbf{P}$ \\
\hline 5 & 0.333 & $P$ \\
\hline 6 & 0.50 & $\mathbf{R}$ \\
\hline 7 & 1.0 & - \\
\hline 8 & 1.0 & - \\
\hline 9 & 0.50 & $\mathbf{R}$ \\
\hline 10 & 1.0 & - \\
\hline 11 & 0.50 & $\mathbf{R}$ \\
\hline 12 & 0.50 & $P$ \\
\hline 13 & 1.0 & - \\
\hline 14 & 1.0 & - \\
\hline 15 & 1.0 & - \\
\hline 16 & 0.50 & $\mathbf{P}$ \\
\hline 17 & 0.50 & $\mathbf{P}$ \\
\hline 18 & 0.50 & $\mathbf{R}$ \\
\hline 19 & 0.50 & $\mathbf{P}$ \\
\hline 20 & 0.50 & $P$ \\
\hline 21 & 0.50 & $\mathbf{P}$ \\
\hline 22 & 0.50 & $\mathbf{P}$ \\
\hline
\end{tabular}

* Postulated homoplasy as indicated by: $\mathrm{P}=$ parallelism; $\mathrm{R}=$ reversal.
(2, cephalic vesicle; 6 , cervical papillae; 9 , synlophe; 18 , spicules).

\section{DISCUSSION}

Phylogenetic analysis of the 6 subfamilies of the Trichostrongylidae resulted in a single phylogenetic tree, which allows recognition of monophyly for the family (Fig. 15). Strong character support was evident for each of the subfamilies, and 2 major clades were postulated. Minimal levels of convergence or parallelism (homoplasy) were required to describe the topology of the tree (Fig. 15; Table II).

Important diagnostic characters may be recognized for the family and each putative clade. Synapomorphies for the family include the length of the fourth ray of the copulatory bursa and the absence of a tail spine in females (Figs. 13, 14). The Graphidiinae clade (Graphidiinae and Ostertagiinae + Haemonchinae) is diagnosed by a high number of ridges comprising the synlophe and large protruding, thornlike cervical papillae. Within the Graphidiinae clade, the sister-group relationship of the Haemonchinae and Osterta- 
giinae is supported by the structure of the dorsal ray and also by the presence of an esophageal tooth and vulval flap. In contrast, the strongly reduced buccal cavity and bursal pattern diagnose the Cooperiinae clade (Cooperiinae and Libyostrongylinae + Trichostrongylinae). Additionally, the extreme reduction or absence of the synlophe further supports recognition of a sister-group relationship for the Trichostrongylinae and Libyostrongylinae.

Before comparing the competing hypotheses for the Trichostrongylidae, the methodological problem of coding polymorphic characters (plesiomorphic versus apomorphic when both states of a character are present) within a supraspecific taxon must be addressed. In such instances, decisions for coding could lead to misinterpretation of relationships. For instance, if a specific character is coded as apomorphic, then the possibility of recognizing secondary reversal within a limited number of taxa is obscured. Conversely, if coded as plesiomorphic, then the application as a synapomorphy at higher levels becomes ambiguous. This situation occurred with respect to the length of the fourth ray of the copulatory bursa in the Ostertagiinae. In the first instance, a long ray would constitute a synapomorphy for the Trichostrongylidae as presented in the current study (with recognition of secondary reversal only in a limited number of genera in the Ostertagiinae). In contrast, a short ray could constitute a plesiomorphy for the Ostertagiinae (interpreted as a secondary reversal for the entire subfamily), thus obscuring acquisition of the derived state in a number of genera.

An alternative interpretation for polymorphism is that the inclusive taxon may not be monophyletic. Limited instances of polymorphism may indicate that some currently recognized subfamilies contain genera that do not belong to the inclusive group. Thus, the necessity of a hierarchical approach where successively lower taxonomic groups are examined is evident. Consequently, if such characters are to be used in phylogenetic reconstruction, complete and accurate definition is requisite. With respect to decisions for other variable characters in the current analysis, coding of states as plesiomorphic or apomorphic did not influence the topology, recognition of sister-group relationships, or length of the tree. However, it did reduce the number of phylogenetically informative characters from 22 to 19.

Alternative evolutionary hypotheses for the
Trichostrongylidae developed by Durette-Desset and Chabaud (1977, 1981), Durette-Desset (1983, 1985, 1992), and Lichtenfels (1987) (from Gibbons and Khalil, 1982) were found to have minimal explanatory power in elucidating the distribution of character states observed among taxa (Figs. 15-17). Compared to the hypothesis presented herein, these earlier attempts at phylogenetic reconstruction were less efficient in explaining character evolution (Tables II-IV) as demonstrated by a lower overall $\mathrm{CI}_{\text {adjusted }}$ and higher HSR $(19.2 \%$ and $51.3 \%$, respectively in Fig. 15; versus $1.1 \%$ and 1.0 in Fig. 16; and $4.0 \%$ and $95.7 \%$ in Fig. 17). These statistics are consistent with a high level of homoplasy in the hypotheses by Durette-Desset $(1983,1985)$ and Lichtenfels (1987), which involved parallelism or reversal for 15 of 22 characters (Tables II-IV; Figs. 15-17). Although each of the subfamilies was recognized in these earlier studies, the reliability of conclusions about phylogeny of the trichostrongylids and relationships among the subfamilies were equivocal (Hoberg and Lichtenfels, 1992; Hoberg et al., 1993b).

Durette-Desset $(1981,1983,1985)$ and Durette-Desset and Chabaud $(1977,1981)$ proposed that the Trichostrongylidae were divided into 3 lineages, depending on the morphology of bursal rays 2 and 3. Each of these lineages was further broken into a "primitive" and "specialized" subfamily based primarily on the structure of the synlophe. The hypothesis developed by DuretteDesset (1985) specified sister-group relationships for 3 distinct lineages (Cooperiinae + Libyostrongylinae; Graphidiinae + Ostertagiinae; Trichostrongylinae + Haemonchinae). However, this topology does not appear to have strong support based on consideration of the morphological data base utilized in the present study. Support for the dendrogram of Durette-Desset (1985) is initially determined and subsequently constrained by the relationship of a single character (bursal rays 2 and 3). Consequently, other characters require multiple trends in parallel and progressive development (specifically characters $5,17,21$, and 22 between the Haemonchinae and the Ostertagiinae defined by character 20; and $3,4,8$, and 10 between the Trichostrongylinae and the Libyostrongylinae + Cooperiinae defined by character 19). Parallelism was not evenly distributed (Fig. 16), with most instances occurring between the Ostertagiinae and Haemonchinae and the Trichostrongylinae and the Libyostrongylinae + Cooperiinae. Additionally, 
the branch with Ostertagiinae + Graphidiinae lacked a defining synapomorphy (Fig. 16).

The putative relationship of the Ostertagiinae and the Graphidiinae has received considerable attention (Durette-Desset, 1981, 1982b, 1985; Jansen, 1989; Hoberg et al., 1993b). DuretteDesset and Chabaud (1981) and Durette-Desset (1985) had suggested derivation of the Ostertagiinae via multiple origins from 2 genera of the Graphidiinae (see summary in Hoberg et al. [1993b]) (Fig. 18A). If this view is correct, by definition the Ostertagiinae would be polyphyletic (derived independently from 1 or more ancestors referred to another taxon), whereas the Graphidiinae would become paraphyletic (a taxon with a common ancestor, but with exclusion of 1 or more descendants) (Hennig, 1966; Wiley, 1981; Wiley et al., 1991). The resulting classification (cladistic or otherwise) would thus have been inconsistent with the phylogenetic history of these trichostrongylid subfamilies (see opinions on classification in Khalil and Gibbons [1981] and Jansen [1989]).

Alternative hypotheses for these subfamilies suggested that the Ostertagiinae and Graphidiinae could be sister-groups (sharing a common ancestor; also not supported due to the absence of a synapomorphy for both subfamilies) (Fig. $18 \mathrm{~B})$, or that the Ostertagiinae and Graphidiinae were more closely related to other subfamilies of Trichostrongylidae (Hoberg et al., 1993b) (Fig. $18 \mathrm{C})$. Resolution of this situation follows from the recognition of putative synapomorphies for the Haemonchinae + Ostertagiinae and unequivocal synapomorphies diagnosing the Ostertagiinae (to the exclusion of the Graphidiinae) presented in the current study (Fig. 15). Thus, the hypothesis for multiple origins of the Ostertagiinae is refuted, and the Graphidiinae as the basal taxon of the Graphidiinae-clade is postulated as the sister-group for the Haemonchinae + Ostertagiinae (Fig. 15).

Aside from the putative phylogeny for the Graphidiinae and Ostertagiinae, the current hypothesis for overall relationships of the subfamilies differs considerably from that proposed by Durette-Desset and Chabaud (1981) and Durette-Desset $(1985,1992)$. The latter hypothesis depicts an implicitly orthogenetic view of evolution (see Brooks and McLennan [1993] for a discussion of the influence of orthogenesis on concepts of parasite evolution). As such, it specifies a primitive and advanced component in each lineage linked by progressive modification or trends in some characters (in this case, parallel trends in evolution of the synlophe and the copulatory bursa).

Consequently, a difference in the proposed mode of evolution may constitute the basis for disparities in these phylogenetic relationships postulated for the Trichostrongylidae. In the hypotheses by Durette-Desset and Chabaud (1977) and Durette-Desset (1982b, 1985), a strong progressive component is evident within each of the 3 lineages (Libyostrongylinae-Cooperiinae; Trichostrongylinae-Haemonchinae; Graphidiinae-Ostertagiinae), which undergo parallel trends in the evolution of specific characters of the synlophe and bursa (Figs. 15, 16; Tables II, III). Orthogenesis or directed evolution, with progressive trends in character development and parallel trends involving a series of primitive and advanced taxa, has been discredited, and hypotheses based on such assumptions are often both teleological and tautological in nature (see Mayr, 1982; Klassen, 1992; Brooks and McLennan, 1993). Although the majority of character polarity decisions in the current analysis are consistent with those developed by Durette-Desset and Chabaud (1977, 1981) and Durette-Desset (1983, 1985) (via a form of outgroup comparison), it was found to be unnecessary to invoke extensive parallelism (for terminal taxa) to explain the evolution of these nematodes. The data matrix applied to the 2 topologies indicates that the current hypothesis is more internally consistent and provides a more efficient explanation for character evolution (Figs. 15, 16; Tables II, III). Thus, the difference in concepts developed for the phylogeny of the subfamilies of the Trichostrongylidae appears to reside not in cladistic methodology, character selection, or character-state polarization, but in the likely mechanisms of evolution.

The relationships presented by Lichtenfels (1987) for 2 major lineages within the Trichostrongylidae also appear to lack strong support (Figs. 15, 17; Tables II, IV). This hypothesis, first outlined by Lichtenfels (1987) only for comparative purposes with the classification proposed by Durette-Desset $(1983,1985)$, was based on a key to genera of the Trichostrongylidae developed by Gibbons and Khalil (1982). The system of Gibbons and Khalil included a variety of characters not evaluated by Durette-Desset (1983): structure of the synlophe, bursa, genital cone, cervical papillae, cephalic vesicle, and buccal tooth. Although the resulting dendrograms differ substantially (Figs. 16, 17), the system of Gib- 


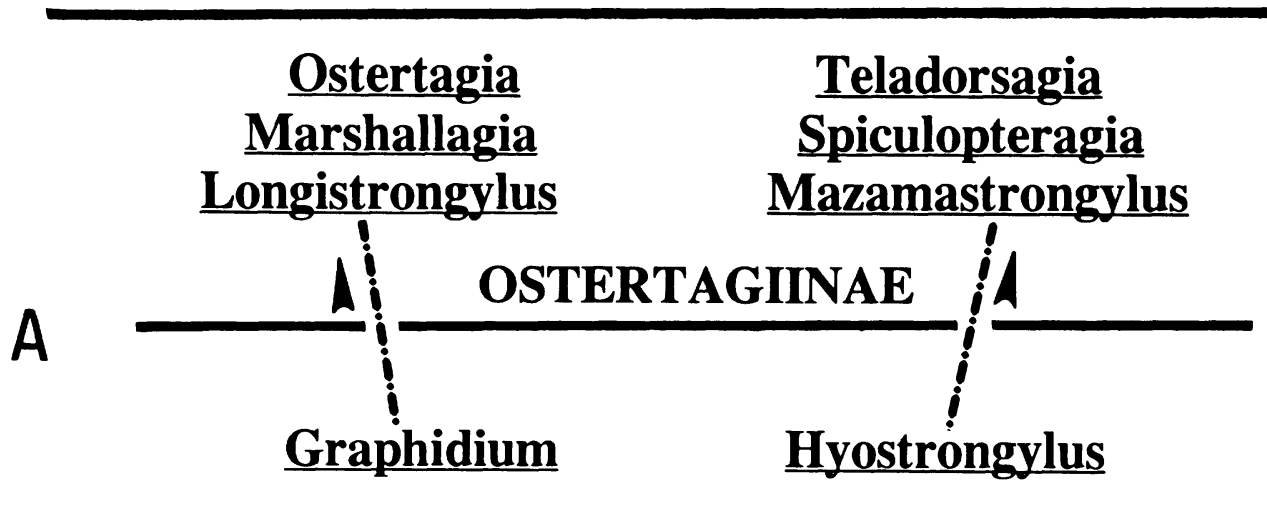

GRAPHIDIINAE

\section{OR}

\section{Ostertagiinae Graphidiinae}

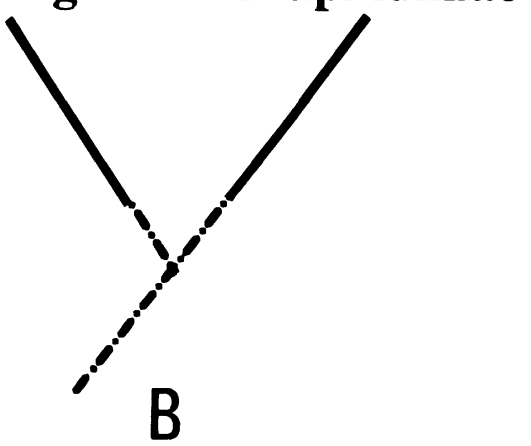

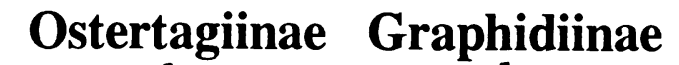
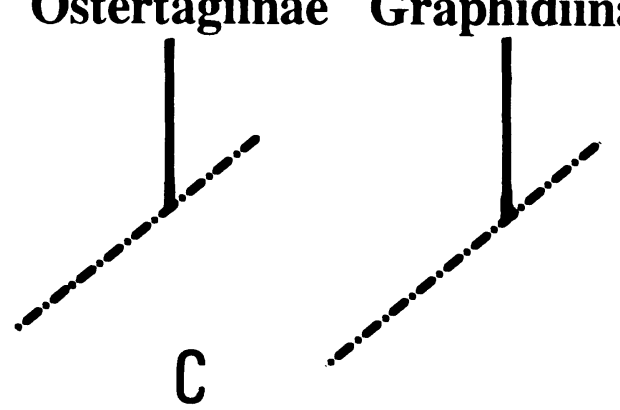

FIGURE 18. Relationships postulated for the Graphidiinae and the Ostertagiinae. 18A. Multiple origins hypothesis for the Ostertagiinae from the Graphidiinae presented by Durette-Desset and Chabaud $(1977,1981)$, and Durette-Desset $(1981,1985)$. Two lineages are recognized within the Ostertagiinae, being derived from either Graphidium or Hyostrongylus; under this scenario Ostertagiinae would be polyphyletic and Graphidiinae paraphyletic. 18B. Alternatively, Graphidiinae could be the sister-group of the Ostertagiinae. 18C. Or, these subfamilies could be more closely related to other subfamilies of the Trichostrongylidae. The hypothesis for independent origins of 2 lineages within the Ostertagiinae was refuted by the current analysis, which recognizes Graphidiinae as the sister-group for the Ostertagiinae + Haemonchinae.

bons and Khalil as interpreted by Lichtenfels (1987) was only marginally more efficient than that of Durette-Desset $(1983,1985)$ (Tables III, IV).
The topology of the current hypothesis and that outlined by Lichtenfels (1987) also differed substantially. In the latter, the basal dichotomy was defined by the presence or absence of the 
synlophe (Libyostrongylinae + Trichostrongylinae and Haemonchinae + Graphidiinae + Cooperiinae and Ostertagiinae). Although the Haemonchinae, Ostertagiinae, and Graphidiinae were grouped together, this clade also included the Cooperiinae in contrast to the present hypothesis (Figs. 15, 17). With respect to the data base for the current study, extensive parallelism and reversal is required to describe the topology of the dendrogram presented by Lichtenfels (1987) (Table IV; Fig. 17), and thus the hypothesis is not considered to be a reliable estimate of phylogeny for the Trichostrongylidae.

\section{Habitat, host, and biogeographic distributions}

Previous attempts at understanding the habitat associations (localization within the host), degree of parasite-host coevolution, and historical biogeography for the trichostrongylids have been limited. Skrjabin et al. (1954) reviewed general aspects of habitat utilization and host distribution (specificity). Durette-Desset and Chabaud $(1977,1981)$ and Durette-Desset (1982a, 1982b, $1985,1992)$ provided a synoptic examination of the relationships of the Trichostrongyloidea and the Trichostrongylidae with respect to their hosts and geographic distributions as an extension of hypotheses for parasite evolution. More inclusively, within the Trichostrongylidae Drózdz (1967) and Jansen (1989) discussed the evolution of the Ostertagiinae and their cervid and bovid hosts. Other considerations have been limited to species-level associations within particular subfamilies, e.g., Hoberg et al. (1993a). Below we provide a preliminary evaluation of the current hypothesis for the trichostrongylids with respect to habitat, hosts, and biogeography.

The evolution of site selection by trichostrongylids may be evaluated with respect to the parasite phylogeny (Fig. 19). Mapping and optimization of data for habitat utilization onto the present phylogeny for the subfamilies allows recognition of the intestine as the ancestral habitat for the family. This conclusion is in agreement with Skrjabin et al. (1954) and corroborated with reference to the intestinal distribution of species of Molineidae (within the Trichostrongyloidea), Strongyloidea, and Ancylostomatoidea (outgroups in the current analysis).

Within the Trichostrongylidae, all members of the Graphidiinae clade occur as adults in the stomach or abomasum of the definitive host. The Cooperiinae clade has species that exclusively utilize the intestine (Cooperiinae), or are found in the stomach and intestine (Libyostrongylinae), or the intestine, stomach, or abomasum of the definitive host (Trichostrongylinae). Thus, if the intestine is the putative ancestral habitat, the stomach/abomasum would have been colonized independently on a minimum of 2 or 3 occasions during the radiation of the family (Fig. 19). A habitat shift is postulated for the ancestor of the Graphidiinae clade to account for the limited distribution of the Graphidiinae, Ostertagiinae, and Haemonchinae in the stomach and abomasum. Within the Cooperiinae clade, the common ancestor of the Libyostrongylinae + Trichostrongylinae may have become associated with the stomach/abomasum while maintaining the ancestral habitat. Alternatively, colonization of a new habitat could have occurred independently within the Trichostrongylinae and the Libyostrongylinae. Refinement of this hypothesis and resolution of the relationships of the Libyostrongylinae and Trichostrongylinae will be dependent upon generic- and species-level analyses within these subfamilies.

\section{Host associations}

The host range of the Trichostrongylidae is rather broad, including a number of avian and mammalian orders, but most genera and species are the predominant nematodes parasitizing ruminants and artiodactyls throughout the world (Durette-Desset and Chabaud, 1977, 1981; Durette-Desset, 1983, 1985). Based on the phylogenetic conclusions summarized by DuretteDesset $(1985,1992)$, the most highly evolved subfamilies, Haemonchinae, Cooperiinae, and Ostertagiinae, are primarily parasites of the Bovidae and Cervidae. However, these subfamilies were not considered to be closely related (summarized in Fig. 16), each having been derived independently from a more primitive subfamily. Thus, parasites present in Bovidae and Cervidae were considered more closely related to those in ratites (Libyostrongylinae + Cooperiinae) or groups of ancient mammals (Graphidiinae + Ostertagiinae and Trichostrongylinae + Haemonchinae), and their current distributions could be explained by colonization rather than coevolution (Durette-Desset, 1985, 1992). An extension of this hypothesis suggested that diversification of the Trichostrongylidae was apparently initiated in the Eocene, with those taxa that occur in modern ruminants having been derived via in- 


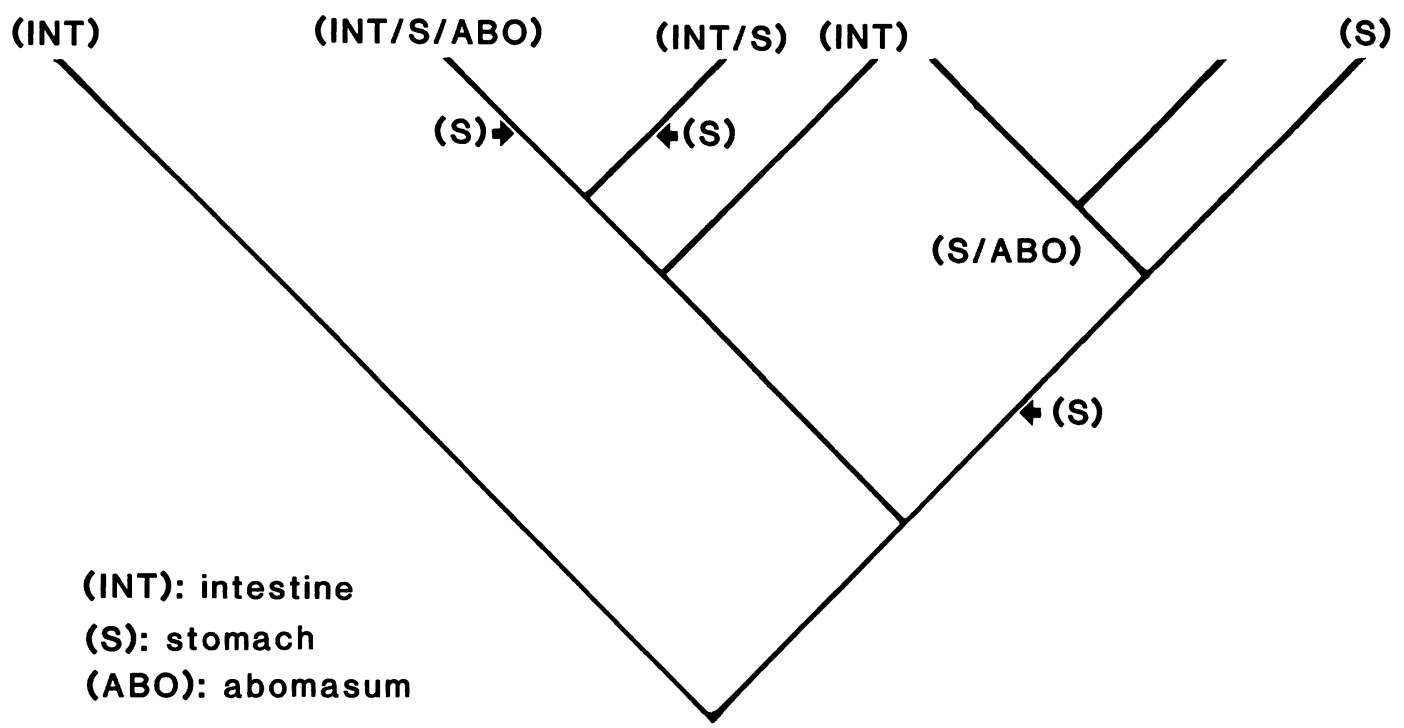

FIGURE 19. Cladogram for the Trichostrongylidae showing the hypothesis presented in the current study with habitat localization in the gastrointestinal system mapped onto the parasite tree. Labels are as follows: INT = intestine, $\mathrm{S}=$ stomach (in nonruminants), and $\mathrm{ABO}=$ abomasum. Relationships depicted are consistent with the intestine as the ancestral habitat; the stomach/abomasum was colonized once in the ancestor of the Graphidiinae clade and once or twice in the Cooperiinae clade to account for the distribution of some species of Libyostrongylinae and Trichostrongylinae.

dependent colonization in the Miocene, coinciding with the origins and radiation of the Bovidae and Cervidae. Additionally, the predominant influence on the distribution, evolution, and radiation of the trichostrongylid fauna was considered to be ecological rather than phylogenetic. Thus, similarity in host diet, specifically herbivory, was recognized as the putative determinant of diversification (Durette-Desset, 1985, 1992).

Jansen (1989) indicated that this scenario for the radiation of the Trichostrongyloidea and Trichostrongylidae did not appear well supported. The phylogenetic analysis presented in the current study provides a mechanism to assess the hypotheses for diversification presented by Durette-Desset $(1985,1992)$. It is clear that host associations are exceedingly complicated, as indicated by the distribution of host groups mapped onto the parasite phylogeny (Fig. 20). This may be indicative that colonization at some level has strongly influenced diversification of this group of nematodes in agreement with concepts (but not specific hypotheses) outlined above. However, in this case the relative importance of host switching versus coevolutionary processes can only be determined in the context of generic-level and species-level analyses of parasites and hosts.
Although this level of resolution is not possible with the current parasite phylogeny, certain generalities about host associations among ruminants are warranted.

The overall distribution of ruminant hosts for the trichostrongylids is compatible with a minimum of 2 events of independent colonization in the Cooperiinae and Graphidiinae clades (Fig. $20)$. Within the former clade, no clear relationships among hosts and subfamilies are apparent, although the Cooperiinae and the Trichostrongylinae occur in ruminants. However, considering the Graphidiinae clade, coevolution of the Haemonchinae and the Ostertagiinae with bovid and cervid hosts appears to have been extensive. The dominance of these subfamilies among the Bovidae, Camelidae, Cervidae, and Antilocapridae indicates that the common ancestor of the Haemonchinae + Ostertagiinae was already a parasite of the pecoran artiodactyls (Fig. 20). Coevolution can secondarily be inferred by refutation of the multiple origins hypothesis of the Ostertagiinae from the Graphidiinae (of DuretteDesset and Chabaud, 1977, 1981) in the present study. With monophyly and a sister-group relationship recognized for the Haemonchinae and Ostertagiinae, it is postulated that radiation of 


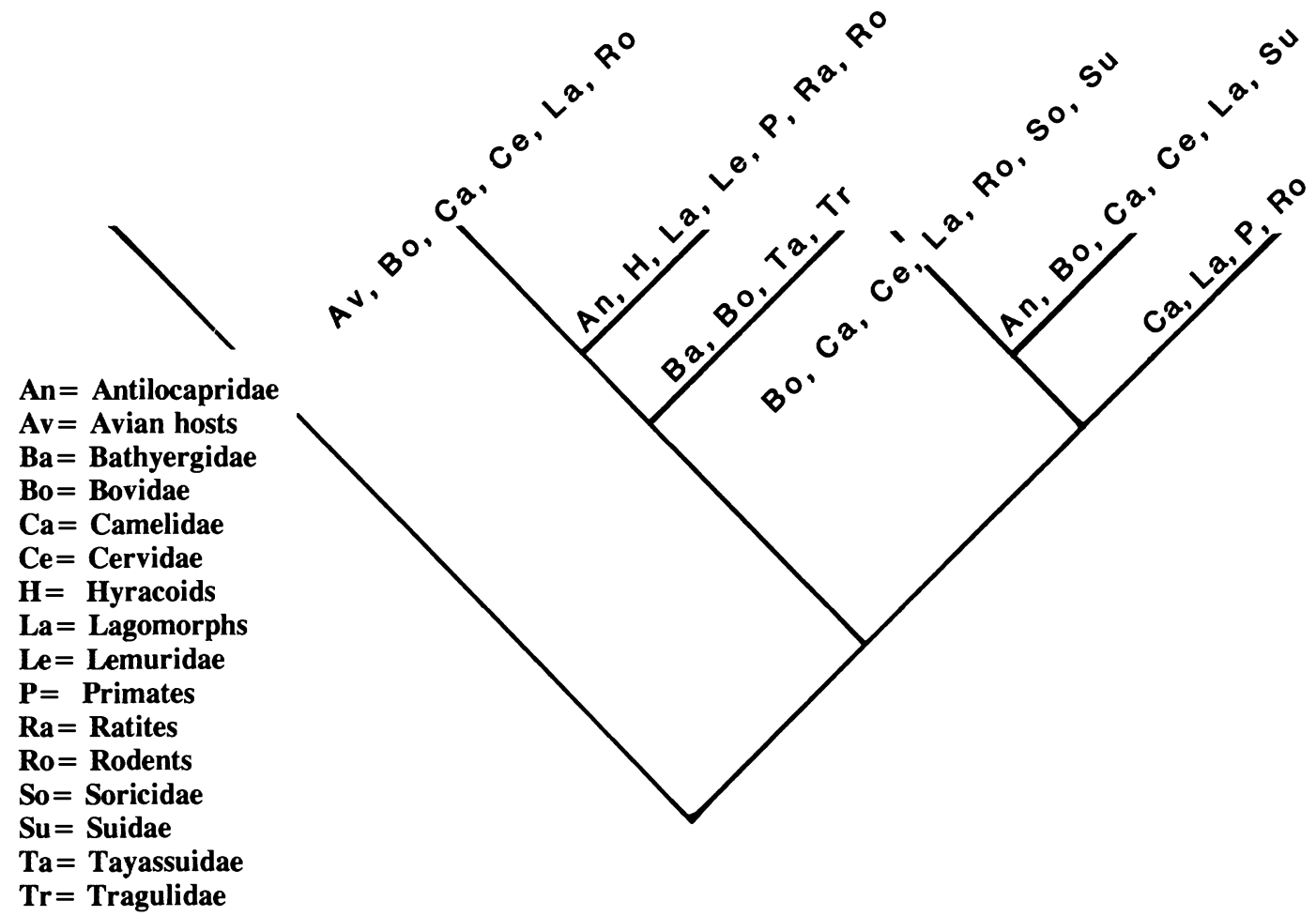

FIGURE 20. Cladogram for the Trichostrongylidae showing the hypothesis presented in the current study and associations with host groups mapped onto the parasite tree.

these taxa coincided with the apparently rapid diversification of basal modern ruminants in the Late Oligocene to Early Miocene about 23-28 million yr ago (see Vrba, 1985; Kraus and Miyamoto, 1991; Allard et al., 1992). With respect to the Ostertagiinae, an hypothesis for extensive coevolution with bovids and cervids had previously been outlined by Drózdz $(1965,1967)$. Based on the present analysis, the hosts for the basal trichostrongylids as the common ancestor of the Cooperiinae + Graphidiinae clades remains to be determined.

\section{Biogeography}

The trichostrongylids are cosmopolitan in distribution, with contemporary ranges occurring across all major biogeographic regions except Antarctica (Fig. 21). Overall these are complex biogeographic relationships that must eventually be considered within the context of paleogeography and paleocontinental reconstruction. Detailed studies within each subfamily are required to elucidate ancestral areas and address the relative importance of dispersal versus vicariance in the development of the fauna. Historically, these geographic ranges have been influenced directly by host biogeography and secondarily by climate, the latter probably as a determinant of the suitability of habitat for development of freeliving larval stages (Jansen, 1989; Suarez and Cabaret, 1991). In the Holarctic, an emergent Beringia connecting Alaska and Chukhotka during much of the Tertiary and intermittently since the late Pliocene (Matthews, 1981; Herman and Hopkins, 1980) was a determinant of distribution for hosts and parasites. Notably, dispersal of Holarctic faunas across Beringia during the Tertiary and their cyclic vicariance and isolation during the Late Pliocene and Quaternary would have directly influenced the diversification of these parasite host assemblages. With respect to Palearctic origins for most ruminant hosts of Cooperiinae, Ostertagiinae, and Haemonchinae, initial diversification of these subfamilies thus appears to have occurred in the Old World (Durette-Desset, 1985, 1992) (Fig. 21). However, in the late Tertiary and Pleistocene the predominant movement of Cervidae and Bovidae was from the Palearctic to the Nearctic (Rausch, 1963; Repenning, 1967; Hoffmann, 1976; Kurtén and 


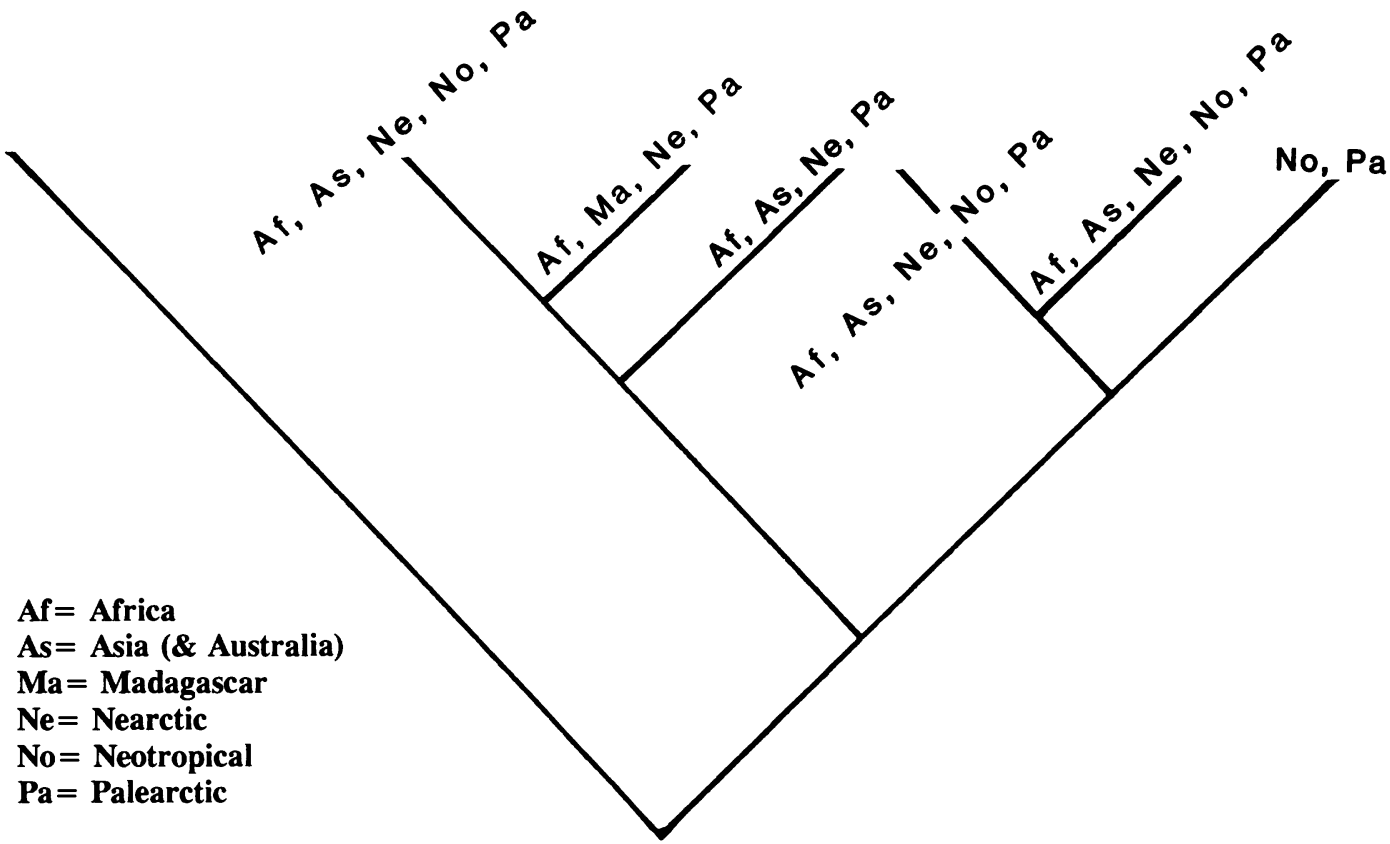

Figure 21. Cladogram for the Trichostrongylidae showing the hypothesis presented in the current study and geographic relationships for taxa mapped onto the parasite tree.

Anderson, 1980; Geist, 1985), and large segments of these faunas may have experienced range expansion into North America during that interval. Thus, for ruminant parasites range expansion would have largely been from west to east across Beringia during the Quaternary (see Hoberg and Rickard, 1988; Hoberg et al., 1989). Likewise, extensive faunal interchange followed the emergence of the Panamanian Isthmus linking North and South America in the Pliocene (Marshall et al., 1982; Vermeij, 1991). With respect to the latter, the extreme isolation of South America through the Tertiary and the recent emergence of a permanent land connection between the Nearctic and Neotropical regions would further refute the putative phylogenetic and biogeographic linkage of the Trichostrongylinae and Haemonchinae proposed by Durette-Desset and Chabaud (1977).

A synoptic elucidation of the historical biogeography of hosts and parasites may be dramatically confounded by the degree of climatological perturbation and habitat fragmentation during the late Pliocene and Quaternary. Isolation in refugial zones during glacial maxima and poststadial vicariance of populations across Beringia appears to have promoted speciation within some assemblages, e.g., Hoberg et al. (1993a).
However, late Pleistocene extinctions of large ruminants could also have had a substantial impact on the fauna. Extirpation and local extinction among many ruminants such as the saiga Saiga tatarica (Linnaeus), Nearctic camelids, and other Pleistocene and Recent mammals, e.g., Guthrie (1968), Kahlke (1991), and Kurtén and Anderson (1980), is likely to have influenced the distributions of some contemporary trichostrongylids. Later domestication of bovids in Eurasia (Epstein and Mason, 1984; Ryder, 1984) and the subsequent transport of infected hosts beyond their typical ranges during contemporary times has secondarily resulted in a broad distribution for many taxa throughout the world, e.g., Andrews (1973) and Rickard et al. (1993). These anthropogenically driven events, and a low level of host specificity for many species of trichostrongyles (Suarez and Cabaret, 1991) will complicate our ability to recover the historical development of host and geographic relationships for the Trichostrongylidae. In this respect, a baseline for assessing the role of contemporary introductions of parasites may be derived from examination of the faunas currently present in exotic ruminants of Australia and New Zealand. Resolution of the biogeographic history for this parasite-host assemblage will follow from anal- 
yses at the level of genera and species of trichostrongyles within the context of paleocontinental reconstruction.

\section{Summary and conclusions}

A preliminary phylogenetic analysis has been developed for the subfamilies of the Trichostrongylidae. The relationships recognized in the current analysis differed markedly from those that have been proposed for this group at the subfamily level. Competing hypotheses suggested quite disparate relationships for the 6 subfamilies (Figs. 15-17; Tables II-IV). The discordance in topology and tree length between the current hypothesis and those presented by Durette-Desset (1985) and Lichtenfels (1987) resulted largely from conclusions about relationships in the latter studies that were based on assessments of single characters, overall morphological similarity, or unique combinations of shared primitive characters. The current hypothesis is strongly supported, requires a lower degree of parallel and convergent evolution, has diagnosable synapomorphies for all branches, and provides a more consistent explanation of character evolution and phylogeny at the subfamilial level. Previous hypotheses for the diversification of the Trichostrongylidae were found to be untenable based on phylogenetic and biogeographic criteria presented in the current study.

Work in progress will attempt to recognize additional morphological characters that define the trichostrongylids and those useful in studying the relationships within the family. The current analyses form the foundation for eventual genericand species-level evaluations of the Ostertagiinae and other subfamilies. In doing so, we hope to elucidate basic concepts in the evolution of the trichostrongyles and other parasitic nematodes and provide a predictive data base with which to evaluate historical biogeography and the interrelationships of coevolution and host switching in the origins and diversification of this economically significant fauna.

\section{ACKNOWLEDGMENTS}

We thank Arthur Abrams for assistance in preparation of the figures. Patricia Pilitt assisted in describing some morphological characters and reviewed an early version of the manuscript. Daniel Brooks and Greg Klassen kindly shared ideas concerning phylogenetic analysis and orthogenesis in evolution. Scott Gardner and Lora
Rickard-Ballweber reviewed and commented on earlier versions of the manuscript.

\section{LITERATURE CITED}

Allard, M. W., M. M. Mryamoto, L. JaRecki, F. Kraus, and M. R. Tennant. 1992. DNA systematics and evolution of the artiodactyl family Bovidae. Proceedings of the National Academy of Sciences USA 89: 3972-3976.

ANDREevA, N. K. 1958. Atlas of helminths (Strongylata) of domestic and wild ruminants of Kazakhstan. Veterinary Institute of the Kazakh Section of VASKhNIL, Tashkent. [English Translation (1978), Agricultural Research Service, United States Department of Agriculture; Amerind Publishing Company, New Delhi, 206 p.]

ANDREwS, J. R. H. 1973. A host-parasite checklist of helminths of wild ruminants in New Zealand. New Zealand Veterinary Journal 21: 43-47.

Baylis, H. A., AND R. DAubNey. 1926. Synopsis of the families and genera of Nematoda. British Museum of Natural History, London, United Kingdom, $277 \mathrm{p}$.

Brooks, D. R., AND D. A. McLennan. 1993. Parascript, parasites and the language of evolution. Smithsonian Institution Press, Washington, D.C., $429 \mathrm{p}$.

Chabaud, A. G. 1959. Remarques sur la systematique des Nématodes Trichostrongyloidea. Bulletin de la Société Zoologique de France 84: 473483 .

- , F. Puylaert, O. Bain, A. J. Petter, ANd M. C. Durette-Desset. 1970. Remarques sur l'homologie entre les papilles cloacales des Rhabdites et les côtes dorsales des Strongylida. Comptes Rendus Hebdomadaires des Séances de l'Academie des Sciences (Paris) 271: 1771-1774.

CrAM, E. 1927. Bird parasites of the nematode suborders Strongylata, Ascaridata, and Spirurata. United States National Museum Bulletin 140: 1465.

DrózDz, J. 1965. Studies on helminths and helminthiases in Cervidae. I. Revision of the subfamily Ostertagiinae Sarwar, 1956 and an attempt to explain phylogenesis of its representatives. Acta Parasitologica Polonica 13: 445-481.

- 1967. Studies on helminths and helminthiases in Cervidae III. Historical formation of helminthofauna in Cervidae. Acta Parasitologica Polonica 14: 287-300.

Durette-Desset, M. C. 1981. A hypothesis on the systematic position of the Ostertagiinae within the Trichostrongylidea. In Workshop no. 14, systematics and biology of Ostertagia sens. lat. (Nematoda: Trichostrongylidae), J. Jansen and L. M. Gibbons (eds.). Parasitology 82: 175-177.

. 1982a. Sur les divisions génériques des Nématodes Cooperiinae. Annales de Parasitologie Humaine et Comparée 57: 383-387.

- 1982b. Sur les divisions génériques des Nématodes Ostertagiinae. Annales de Parasitologie Humaine et Comparée 57: 375-381.

. 1983. Keys to the genera of the superfamily Trichostrongyloidea. No. 10. In CIH keys to the 
nematode parasites of vertebrates, R. C. Andersor and A. G. Chabaud (eds.). Commonwealth Agricultural Bureaux, Farnham Royal, England, p. 186.

1985. Trichostrongyloid nematodes and their vertebrate hosts: Reconstruction of the phylogeny of a parasitic group. Advances in Parasitology 24: 239-306.

- 1989. Nomenclature proposée pour les espèces décrites dans la sous-famille des Ostertagiinae Lopez-Neyra, 1947. Annales de Parasitologie Humaine et Comparée 64: 356-373.

- 1992. Phylogenie des nematodes Trichostrongyloidea vue a travers celle de leurs hotes vertebres. Parassitologia 34: 1-16.

- , AND A. G. Chabaud. 1977. Essai de classification des Nématodes Trichostrongyloidea. Annales de Parasitologie Humaine et Comparée 52: 539-558.

$\longrightarrow$, AND - 1981. Nouvel essai de classification des Nématodes Trichostrongyloidea. Annales de Parasitologie Humaine et Comparée 56: 297-312.

— AND —. 1993. Nomenclature des Strongylidae au-dessus du groupe-famille. Annales de Parasitologie Humaine et Comparée 68: 111-112.

Epstein, H., AND I. L. Mason. 1984. Cattle. In Evolution of domesticated animals, I. L. Mason (Ed.). Longman Inc., New York, New York, p. 6-27.

$\rightarrow$ GeIST, V. 1985. On Pleistocene bighorn sheep: Some problems of adaptation, and relevance to today's American megafauna. Wildlife Society Bulletin 13: 351-359.

GibBons, L. M. 1977. Revision of the genera Longistrongylus LeRoux 1931, Kobusinema Ortlepp, 1963 and Bigalkenema Ortlepp, 1963 (Nematoda: Trichostrongylidae). Journal of Helminthology 51: 41-62.

- 1979. Revision of the genus Haemonchus Cobb, 1898 (Nematoda: Trichostrongylidae). Systematic Parasitology 1: 3-24.

- 1981. Revision of the African species of the genus Cooperia Ransom, 1907 (Nematoda, Trichostrongylidae). Systematic Parasitology 2: 219-252.

$\longrightarrow$, AND L. F. KHALIL. 1982. A key for the identification of genera of the nematode family Trichostrongylidae Leiper, 1912. Journal of Helminthology 56: 185-233.

— AND —. 1983. Morphology of the genital cone in the nematode family Trichostrongylidae and its value as a taxonomic character. In Concepts of nematode systematics, A. R. Stone, H. M. Platt, and L. F. Khalil (eds.). Systematics Association Special Volume 22, Academic Press, London, United Kingdom, p. 261-271.

Glen, D. R., AND D. R. BROOKS. 1985. Phylogenetic relationships of some strongylate nematodes of primates. Proceedings of the Helminthological Society of Washington 52: 227-236.

$\rightarrow$ Guthrie, R. D. 1968. Paleoecology of the largemammal community in interior Alaska during the Late Pleistocene. American Midland Naturalist 79 346-363.

HenNIG, W. 1966. Phylogenetic systematics. University of Illinois Press, Urbana, 263 p.
Herman, Y., AND D. M. HopkIns. 1980. Arctic Ocean climate in late Cenozoic time. Science 209: 557562.

Hoberg, E. P., AND J. R. LichtenFEls. 1992. Morphology of the synlophe and genital cone of $\mathrm{Pa}$ rostertagia heterospiculum (Trichostrongylidae) with comments on the subfamilial placement of the genus. Systematic Parasitology 22: 1-16.

M. FRUETEL, AND L. G. RICKARD. 1989. Synlophe of Nematodirus odocoilei (Trichostrongyloidea) from deer and caribou in North America with comments on the evolution of Nematodirus spp. among the Cervidae (Artiodactyla). Canadian Journal of Zoology 67: 1489-1494.

- J. R. Lichtenfels, AND P. A. Pilitt. 1993a. Comparative morphology of Ostertagia mossi and Ostertagia dikmansi (Trichostrongylidae) from Odocoileus virginianus and comments on other Ostertagia spp. from the Cervidae. Systematic Parasitology 24: 111-127.

- 1 1993b. Synlophe of Hyostrongylus rubidus (Trichostrongylidae), with evaluation of structural characters supporting affiliation with the Ostertagiinae. Journal of the Helminthological Society of Washington 60: 219-233.

,- 1 , AND - . Synlophe of Cooperia neitzi (Trichostrongylidae: Cooperiinae) with comments on vulval inflations and hypertrophy of cuticular ridges among the trichostrongylids. Journal of the Helminthological Society of Washington 60: 153-161.

—, AND L. G. RICKARD. 1988. Morphology of the synlophe of Nematodirus maculosus (Trichostrongyloidea) with comments on the evolution of Nematodirus spp. among the Caprinae (Artiodactyla). Proceedings of the Helminthological Society of Washington 55: 160-164.

HofFMANN, R. S. 1976. An ecological and zoogeographical analysis of animal migration across the Bering land bridge during the Quaternary Period. In Beringia in the Cenozoic, V. L. Kontrimavichus (ed.). Akademia Nauk, SSSR, Vladivostok, Russia, p. 354-367.

JANSEN, J. 1989. A concise history of the Ostertagiinae Lopez-Neyra, 1947 (Nematoda: Trichostrongyloidea) and a discussion on its composition. Acta Leidensia 58: 151-159.

KAHLKE, R.-D. 1991. Pleistocene distributional and evolutionary history of the genus Saiga Gray, 1843 (Mammalia, Artiodactyla, Bovidae) in the Palearctic. Vertebrata Palasiatica 29: 314-322.

Khalil, L. F., AND L. M. Gibbons. 1981. The subfamily Ostertagiinae Sarwar, 1956. Parasitology 82: 177-181.

$\rightarrow$ KLASSEN, G. J. 1992. Coevolution: A history of the macroevolutionary approach to studying hostparasite associations. Journal of Parasitology 78: 573-587.

$\rightarrow-$ R. D. MooI, AND A. Locke. 1991. Consistency indices and random data. Systematic Zoology 40: 446-457.

KraUs, F., AND M. M. Mryamoto. 1991. Rapid cladogenesis among the pecoran ruminants: Evidence from mitochondrial DNA sequences. Systematic Zoology 40: 117-130. 
Kurtén, B., AND E. Anderson. 1980. Pleistocene mammals of North America. Columbia University Press, New York, New York, 442 p.

LANCASTER, M. B., AND C. HoNG. 1990. The identification of females within the subfamily Ostertagiinae Lopez-Neyra, 1947. Veterinary Parasitology 35: 21-27.

LEIPER, R. T. 1912. Check-list of helminthes parasitic in cattle. Journal of the London School of Hygiene and Tropical Medicine 1: 115-123.

LICHTENFELS, J. R. 1977. Differences in cuticular ridges among Cooperia spp. of North American ruminants with an illustrated key to species. Proceedings of the Helminthological Society of Washington 44: 111-119.

- 1987. Phylogenetic inference from adult morphology in the Nematoda; with emphasis on the bursate nematodes, the Strongylida; advancements (1982-1985) and recommendations for further work. International Journal for Parasitology 17: 269-279.

- AND E. P. HoBERG. 1993. The systematics of nematodes that cause ostertagiasis in domestic and wild ruminants in North America: An update and a key to species. Veterinary Parasitology 46: 3353.

LUNDBERG, J. G. 1972. Wagner networks and ancestors. Systematic Zoology 21: 398-413.

Marshall, L. G., S. D. WebB, J. J. Sepkoski, JR., AND D. M. RAUP. 1982. Mammalian evolution and the great American interchange. Science 215: 13511357.

MatThews, J. V., JR. 1981. Tertiary and Quaternary environments: Historical background for an analysis of the Canadian insect fauna. Memories of the Entomological Society of Canada 108: 31-86.

MAYR, E. 1982. Processes of speciation. In Mechanisms of speciation, C. Barigozzi (ed.). Liss, Nev York, New York, p. 1-19.

$\rightarrow$ MeIer, R., P. Kores, AND S. DARwin. 1991. Homoplasy slope ratio: A better measurement of observed homoplasy in cladistic analyses. Systematic Zoology 40: 74-88.

RAUSCH, R. L. 1963. A review of the distribution of Holarctic Recent mammals. In Symposium on $\mathrm{Pa}-$ cific Basin biogeography, J. L. Gressit (ed.). Tenth Pacific Science Congress, Bishop Museum Press, Honolulu, Hawaii, p. 29-43.

RePENNING, C. A. 1967. Palearctic-Nearctic mammalian dispersal in the Late Cenozoic. In The Bering landbridge, D. M. Hopkins (ed.). Stanford University Press, Stanford, California, p. 288-311.

RickARD, L. G., AND J. R. LiCHTENFELS. 1989. Nematodirus archari (Nematoda: Trichostrongyloidea) from ruminants in North America with a description of the synlophe and the female. Canadian Journal of Zoology 67: 1708-1714.

- E. P. Hoberg, N. M. Allen, G. L. Zimmerman, AND T. M. CRAIG. 1993. Spiculopteragia spiculoptera and $S$. asymmetrica (Nematoda: Trichostrongyloidea) from red deer (Cervus elaphus) in Texas. Journal of Wildlife Diseases 29: 512-515.

RYDER, M. L. 1984. Sheep. In Evolution of domesticated animals, I. L. Mason (ed.). Longman Inc., New York, New York, p. 63-85.

SARWAR, M. M. 1956. Studies on some trichostrongylids of ruminants from the Indo-Pakistan sub-continent. Biologia 2: 145-215.

SkrJabin, K. I., N. P. Shikhobalova, and R. S. SHUL'Ts. 1954. Essentials of nematodology III. Trichostrongyloids of animals and man. Moscow, Academy of Sciences USSR. [English Translation by Israel program for Scientific Translations, Jerusalem, 1960, $704 \mathrm{p}$.]

,,--- T. I. Popova, S. N. BoEv, AND S. L. Deliamure. 1952. Keys to the parasitic nematodes III. Strongylata. Moscow, Academy of Sciences USSR. [English Translation by Israel Program for Scientific Translations, Jerusalem, 1961,890 p.]

SuARez, V. H., AND J. Cabaret. 1991. Similarities between species of the Ostertagiinae (Nematoda: Trichostrongyloidea) in relation to host-specificity and climatic environment. Systematic Parasitology 20: 179-185.

SwoFFORD, D. L. 1985. Phylogenetic analysis using parsimony, version 2.4. Illinois Natural History Survey.

Travassos, L. 1937. Revisao da familia Trichostrongylidae Leiper, 1912. Monographias Instituto Oswaldo Cruz 1: 1-512.

VERMEI, G. J. 1991. When biotas meet: Understanding biotic interchange. Science 253: 1099-1 104.

VRBA, E. S. 1985. African Bovidae: Evolutionary events since the Miocene. South African Journal of Science 81: 263-266.

WILEY, E. O. 1981. Phylogenetics, the theory and practice of phylogenetic systematics. John Wiley and Sons, Inc., New York, New York, 439 p.

-, D. Siegel-Causey, D. R. BROOKS, AND V. A. FuNK. 1991. The compleat cladist. A primer of phylogenetic procedures. University of Kansas, Museum of Natural History, Special Publication $19,158 \mathrm{p}$.

YORKE, W., AND P. A. MAPLESTONE. 1926. The nematode parasites of vertebrates. J. and A. Churchill, London, U.K., 536 p. 